\title{
Experimental Studies on Seakeeping and Maneuverability of Ships in Adverse Weather Conditions
}

Article in Journal of Ship Research · September 2017

DOI: $10.5957 / J O S R .170002$

CITATIONS

0

7 authors, including:

ค Florian Sprenger

2. Forschungszentrum Jülich

47 PUBLICATIONS 102 CITATIONS

SEE PROFILE

Guillaume Delefortrie

Vlaams Ministerie van Mobiliteit en Openbare Werken

44 PUBLICATIONS 132 CitATIONS

SEE PROFILE
READS

269

Adolfo Maron

INTA-CEHIPAR

7 PUBLICATIONS 17 CITATIONS

SEE PROFILE

Thibaut Van Zwijnsvoorde

Ghent University

3 PUBLICATIONS 5 CITATIONS

SEE PROFILE

Some of the authors of this publication are also working on these related projects:

HYDRODYNAMIC ANALYSIS AND PRELIMINARY DESIGN OF A SWATH HIGH-SPEED FERRY View project

Invited Lectures View project 
Journal of Ship Research, Vol. 61, No. 3, September 2017, pp. 131-152

http://dx.doi.org/10.5957/JOSR.170002

\title{
Experimental Studies on Seakeeping and Maneuverability of Ships in Adverse Weather Conditions
}

\author{
Florian Sprenger, ${ }^{*}$ Adolfo Maron, ${ }^{\dagger}$ Guillaume Delefortrie, ${ }^{\ddagger}$ Thibaut van Zwijnsvoorde, ${ }^{7}$ Andrés Cura-Hochbaum, ${ }^{\$}$ \\ Antonio Lengwinat, ${ }^{\S}$ and Apostolos Papanikolaou"l \\ *MARINTEK, Trondheim, Norway \\ ${ }^{\dagger}$ CEHIPAR, Madrid, Spain \\ ${ }^{\ddagger}$ Flanders Hydraulics Research, Antwerp, Belgium \\ "Ghent University, Ghent, Belgium \\ ${ }^{\S}$ Technische Universität Berlin, Berlin, Germany \\ "Ship Design Laboratory, National Technical University of Athens, Zografou, Greece
}

The introduction of the energy efficiency design index (EEDI), which is applicable for various types of new-built ships after January 1, 2013, raised concerns regarding the sufficiency of propulsion power and steering devices to maintain maneuverability in adverse conditions. This was the motivation for the initiation of the EU research project SHOPERA (Energy Efficient Safe SHip OPERAtion, 2013-2016, http://www.shopera.org). The aim of this article is the development of suitable methods, tools, and guidelines to effectively address the above concerns and to enable safe and green shipping. Within the framework of SHOPERA, a comprehensive experimental program of more than 1300 different model tests for three ship hulls of different geometry and hydrodynamic characteristics has been conducted by four leading European maritime experimental research institutes: MARINTEK, Norway; CEHIPAR, Spain; Technische Universität Berlin, Germany; and Flanders Hydraulics Research, Belgium. The tested hull types refer to two public domain designs, namely the KVLCC2 tanker and the Duisburg Test Case (DTC) container ship, as well as to a small RoPax ferry design, which is a proprietary hull design of a member of the SHOPERA consortium. The conducted tests were distributed among the four research institutes to benefit from the unique possibilities of each facility and to gain added value by establishing data sets for the same hull model and test type at different under keel clearances. This article presents the scope of the SHOPERA model test program for the two public domain hull models - the KVLCC2 and the DTC. The main particulars and loading conditions for the two vessels as well as the experimental setup is provided to support the interpretation of the experimental data that is presented. The focus lies on the added resistance and drift forces at zero and moderate forward speed, propulsion, and rudder force tests in waves and the assessment of maneuverability of ships in waves, as compared to calm water conditions.

Keywords: EEDI; IMO; minimum powering; seakeeping; maneuverability; added resistance; drift forces; adverse conditions; model testing; shallow water

\section{Introduction}

Manuscript received at SNAME headquarters May 27, 2017; revised manuscript received June 12, 2017.

The original manuscript was presented at the SNAME Maritime Convention in Bellevue, WA, November 1-4, 2016.
The background of the presented research work is the implementation of the energy efficiency design index (EEDI) by the International Maritime Organization (IMO) in January 2013 (IMO 2013a, 2013b) and the associated requirement for all new-built 
vessels to meet EEDI reference lines for $\mathrm{CO}_{2}$ emissions. The simplest way to fulfil these requirements is to reduce the installed power. This approach may, however, lead to significant safety issues for some ship types, since ship's maneuvering capabilities in adverse conditions might not be sufficient anymore. The EU research project SHOPERA (Energy Efficient Safe SHip OPERAtion) (Papanikolaou et al. 2014; Papanikolaou et al. 2015a, 2015b, 2015c; Sprenger et al. 2016) dealt with this problem by developing proper methods and rational procedures for the assessment of ship's maneuverability in adverse weather conditions. In the frame of this project, a comprehensive model testing program of more than 1300 different tests for three modern hull designs (the Duisburg Test Case [DTC] postPanamax container vessel, the KVLCC2 tanker, and a RoPax ferry) of different hydrodynamic characteristics was conducted. This test program was shared among four European test facilities, namely MARINTEK (leader), CEHIPAR, Flanders Hydraulics Research (FHR), and Technische Universität Berlin (TUB). The aim of the model tests in SHOPERA was to close gaps in available benchmark data and broaden the database test results for benchmarks of ship's maneuvering in waves and seakeeping. By selecting three distinct hull model types and exploiting the unique capabilities of the participating four different model test facilities, valuable insights into the seakeeping and maneuvering characteristics of the test vessels and the various used experimental techniques were gained. All obtained results contributed to the development of a model test database for project SHOPERA, which was used for the validation of numerical methods/software tools and empirical methods. The most significant part of these data was used for an international benchmark study, which was organized by the SHOPERA project in 2016. A comprehensive report about this benchmark can be downloaded from the SHOPERA web site (http://www.shopera.org) (Liu et al. 2016). On the basis of the conducted numerical and experimental research work, along with a series of design case studies, it was possible to develop a rational assessment procedure for ship's performance in adverse weather conditions and to formulate meaningful minimum powering requirements to ensure safe ship operation in adverse weather conditions, while keeping the right balance between ship economy, efficiency, and safety of the ship and the environment (see, IMO 2016a-2016c).

\subsection{State of the art on experimental studies}

Several experimental studies on the added resistance of ships in waves were conducted in the past for different hull types, mainly in regular head wave conditions. Experimental data for the added resistance were publicly available for the Series 60 hull forms and a destroyer hull (Strom-Tejsen et al. 1973), the S175 standard container ship and some full-type hull forms (Fujii \& Takahashi 1975), and the Wigley hull (Journée 1992). More recently, valuable experimental data were published for the KVLCC2 standard tanker in regular head waves at different speeds (Guo \& Steen 2010) and for varying wave amplitudes (Yasukawa et al. 2016). An uncertainty analysis for the added resistance experiments of the KVLCC2 was conducted by Park et al. (2015).

Regarding the employed experimental techniques, methods for the measurement of the mean wave forces "at zero speed" with active and passive restraints were presented earlier by Pinkster (1980) and Huijsmans (1996). "At forward speed," mean wave force validation data in "oblique" waves were made available for the SR108 container for a variety of wave lengths (Yasukawa \& Adnan 2006). A wave force measurement campaign for two cruise ship models of higher speed was more recently published (Valanto \& Hong 2015), providing data for many wave encounter angles. Another published study presented a free/captive hybrid method for the maneuvering prediction in waves using a modified Planar Motion Mechanism (PMM) dynamometer for operation in waves (Xu et al. 2007). A different approach to the mean wave force measurement was presented for two modified Wigley hull models sailing in fixed and freely oscillating condition in waves (Kashiwagi 2013), where the forces are measured once directly and alternatively by deriving them from the energy of the ship-generated wave systems. In all publications on mean force measurements mentioned earlier, the mean forces in regular waves are just average values over a number of complete encountering periods. In several cases, it seems that the hydrodynamic inertial forces were not taken into account and possible influences of the experimental setup were neglected. Once the mean wave forces are determined (either experimentally or numerically) for the desired wave lengths and all encountering angles, it is possible to postprocess them in a coefficient-based calm water mathematical model and predict maneuvers in waves (Yasukawa \& Nakayama 2009; Cura-Hochbaum \& Uharek 2016).

Notable published experimental studies on the effect of waves on the maneuvering characteristics of free sailing models comprise the pioneering studies on turning ability of a RoRo ship in regular waves (Hirano et al. 1980) and studies on the KVLCC2 model for various wave lengths and wave amplitude ratios (Lee et al. 2009). Free sailing maneuvering tests, comprising zig-zag and turning circle tests in calm water and in waves, have been also performed for Very Large Crude Carrier (VLCC)s by Ueno et al. (2003) and Yasukawa et al. (2015).

The availability of experimental data was indispensable for the development and validation of alternative theoretical/numerical methods for the estimation of the added resistance of ships in waves over the years (International Towing Tank Conference [ITTC] 2014; Maruo 1963; Boom et al. 2013). They also formed the basis for the development of semiempirical corrections for the added resistance in short-wave regimes (see Faltinsen et al. 1980) and approximate formulas for the entire wave length range (e.g., Liu \& Papanikolaou 2016).

\subsection{The tested ship models}

The KVLCC2 is a VLCC-type vessel, representing the second variant of a modern tanker design developed by the Korean Institute

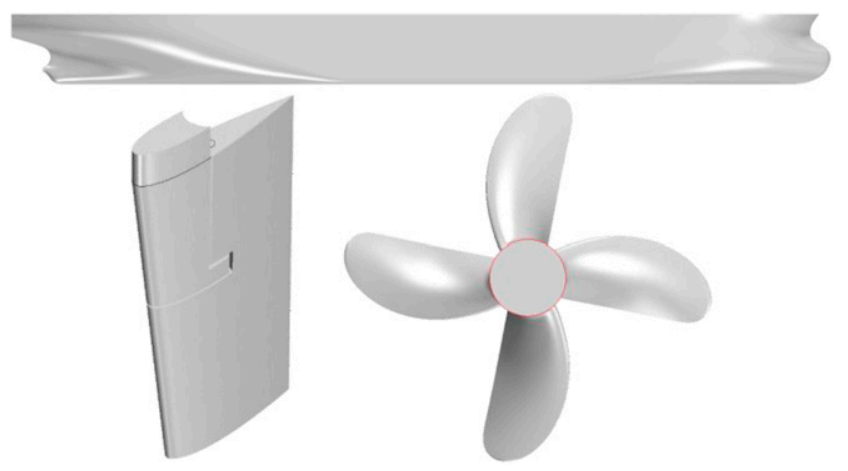

Fig. 1 View of the KVLCC2 hull (top), the rudder (bottom, left) and the propeller (bottom, right) 
Table 1 Main particulars and loading conditions for the KVLCC2 and DTC (all values refer to the origin located at [AP/CL/BL])

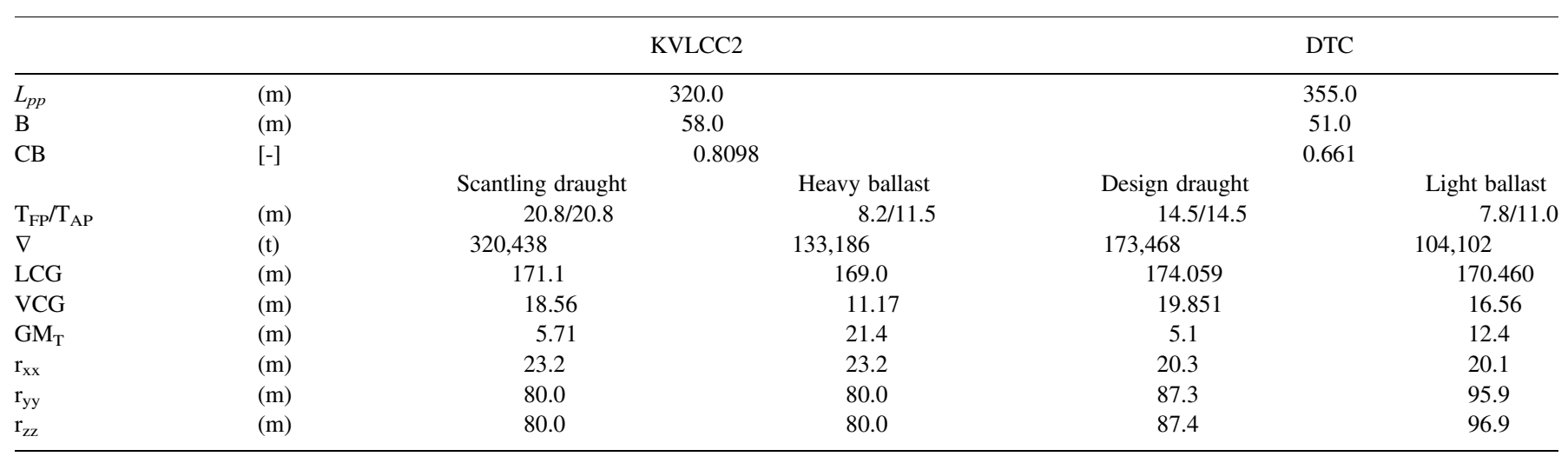

[-] indicate dimensionless values

of Ship and Ocean Engineering with a bulbous bow and U-shaped stern lines (see Fig. 1 and SIMMAN 2008). The hull lines have been exclusively developed for testing and benchmarking. The KVLCC2 design features a horn rudder of $273.3-\mathrm{m}^{2}$ rudder area and a lateral area of $136.7 \mathrm{~m}^{2}$. The tanker is equipped with a fixed-pitch four-bladed propeller of 9.86-m full-scale diameter and a pitch ratio of $\mathrm{P} / \mathrm{D}_{0.7}=$ 0.721 . The direction of rotation is right handed, looking in the positive $\mathrm{x}$-direction. The main particulars of this vessel and the loading conditions of the model for scantling draught and heavy ballast are given in Table 1 in full scale. Within the SHOPERA project, the KVLCC2 design has been tested in deep water at CEHIPAR (scale 1:80) and in shallow water conditions at Flanders Hydraulics (scale 1:75).

The DTC design is a postPANAMAX 14,000 TEU container vessel. It has been developed at the Institute of Ship Technology, Ocean Engineering and Transport Systems of the University of Duisburg-Essen for benchmarking and validation of numerical methods and its lines are available to the public (see Fig. 2 and El Moctar et al. 2012).

The DTC design features a twisted rudder with Costa bulb and a NACA 0,018 base profile (see Fig. 2, bottom left). The projected area of the movable part of the rudder is $95.1 \mathrm{~m}^{2}$ and the total rudder area is $255.0 \mathrm{~m}^{2}$. Figure 2 (bottom right) shows the fixed-pitch fivebladed propeller of 8.911-m full-scale diameter with a pitch ration of $\mathrm{P} / \mathrm{D}_{0.7}=0.959$. The direction of rotation is right handed, looking in positive $\mathrm{x}$-direction. On each side of the vessel, a segmented bilge keel is placed symmetrically around the midship section, consisting of five segments, each with $14.85 \mathrm{~m}$ length and $0.4 \mathrm{~m}$ profile height. The gap width between the segments is $3.0 \mathrm{~m}$. The main particulars of this vessel and the loading conditions of the model for the design draught and light ballast are given in Table 1 in full scale. Within the SHOPERA project, the DTC design has been tested in deep water at MARINTEK (scale 1:63.65) and in shallow/intermediate water conditions at TUB and FHR (scale 1:89.11).

\subsection{The testing facilities}

The ambitious test program in SHOPERA was shared among four European test facilities, namely MARINTEK (leader), CEHIPAR, FHR, and TUB.

1.3.1. MARINTEK. The majority of tests in head and following seas at MARINTEK have been performed in the towing tank, which is $260 \mathrm{~m}$ long, $10.5 \mathrm{~m}$ wide, and $10 \mathrm{~m}$ deep, on a $80-\mathrm{m}$ long section from the wave maker. The water depth in the remaining part is $5.6 \mathrm{~m}$. A double flap wave maker is able to generate waves in a period range between 0.56 and $10.0 \mathrm{sec}$. The tests in oblique seas as well as free running maneuvers were performed in the ocean basin, which is $80 \mathrm{~m}$ long, $50 \mathrm{~m}$ wide, and features a movable bottom, allowing for water depths between 0 and $10 \mathrm{~m}$. The head and one side of the basin are equipped with 144 multiflap double and a double flap wave maker, respectively, to generate long- and short-crested seas.

1.3.2. CEHIPAR. Tests at CEHIPAR have been performed in the Ship Dynamics laboratory. This basin is $150 \mathrm{~m}$ long, $30 \mathrm{~m}$ wide, and $5 \mathrm{~m}$ deep. Close to the wave maker, it features a pit of $10 \mathrm{~m}$ by $10 \mathrm{~m}$ with a depth of $10 \mathrm{~m}$.

1.3.3. Flanders Hydraulics Research. At FHR, model tests have been performed in the Towing Tank for Maneuvers in Shallow Water (cooperation with Ghent University, see Delefortrie et al. 2016). The tank is equipped with a wave maker and has the exploitable dimensions of $68 \mathrm{~m} \times 7 \mathrm{~m} \times 0.5 \mathrm{~m}$.

1.3.4. Technische Universität Berlin. All model tests at TUB have been carried out in the shallow seakeeping basin of the former Berlin Model Basin Very Large Crude Carrier (VLCC). The basin is $110 \mathrm{~m}$ long with a maximum testing length of $90 \mathrm{~m}$. The width of the

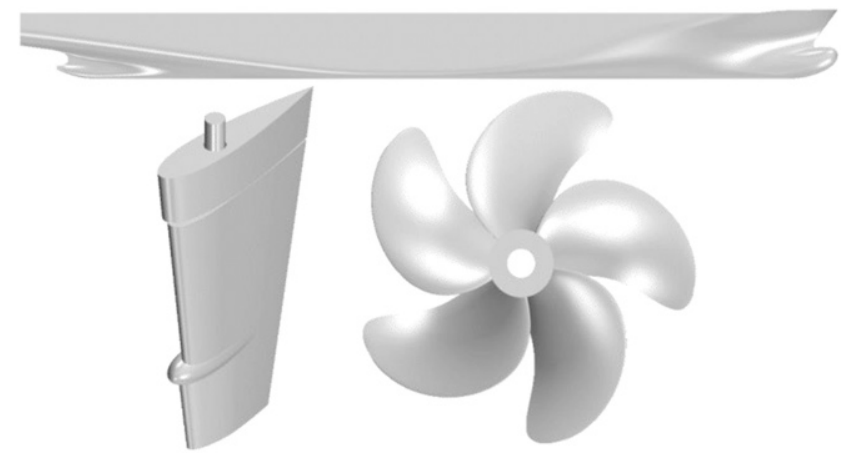

Fig. 2 View of the DTC hull (top), the rudder (bottom, left) and the propeller (bottom, right) 
basin is $8 \mathrm{~m}$ and the water depth is adjusted to $1 \mathrm{~m}$. The electrical wave generator is fully controlled from the towing carriage by computer.

\section{Added resistance and drift forces}

The added resistance and drift force tests have been conducted in steep regular waves and selected irregular sea states, while the latter are not presented in this article. At MARINTEK, the wave climates have been generated along the limiting curves of the wave makers in a range of $0.1 \leq \lambda / L_{p p} \leq 1.2$. Individual adjustments of the wave heights have been made during testing to guarantee the safety of the hull models and measuring equipment. At the peak of the Response Amplitude Operator (RAO)s and for the shortest wave lengths, two additional wave amplitudes have been tested to account for possible nonlinear effects. Because of the high wave steepness and the extension of the testing range into oblique seas and the short relative wave length region (diffraction dominant domain), the results obtained at MARINTEK offer valuable insights and contribute to an enhanced benchmark and validation database compared to the currently available state of the art.

For data comparison purposes, all mean forces and moments of the ship model at zero speed in waves are presented in the following nondimensional form:

$$
F^{\prime}=\frac{F}{\rho g \zeta_{a}^{2} \frac{B^{2}}{L_{P P}}} \quad M^{\prime}=\frac{M}{\rho g \zeta_{a}^{2} B L_{P P}}
$$

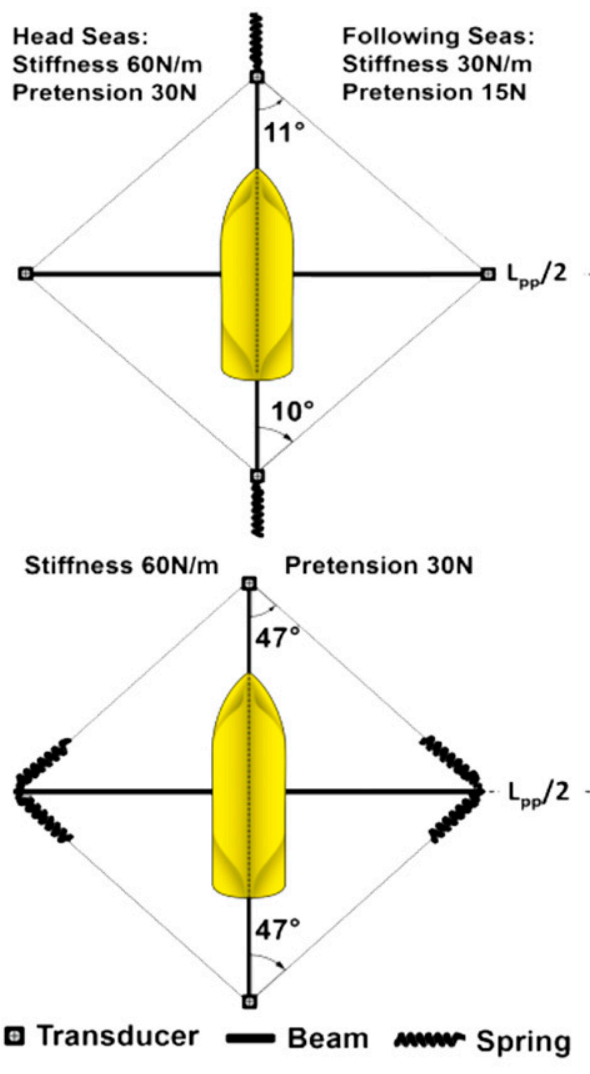

At forward speed, the nondimensional added resistance force $R_{\mathrm{AW}}^{\prime}$ is obtained in a similar manner, while subtracting from the measured total resistance in waves $R_{W}$ the calm water resistance $R_{0}$.

$$
R_{\mathrm{AW}}^{\prime}=\frac{R_{W}-R_{0}}{\rho g \zeta_{a}^{2} \frac{B^{2}}{L_{P P}}}
$$

The following conventions apply to the presented results:

1) A right-handed coordinate system applies, with the $x$-axis pointing to the bow, the $\mathrm{y}$ axis to the port side and the $\mathrm{z}$ axis is positive upwards.

2) The incident wave heading angle $\mu$ (Greek mu) is $180^{\circ}$ for head waves.

\subsection{Experimental setup DTC, deep water}

For the added resistance tests in deep water at MARINTEK, the DTC model was captive in a soft-mooring arrangement as visualized in Fig. 3 and towed by the carriage at constant speed. Lightweight lines were used and the spring stiffness has been chosen such that the eigenfrequency of the mooring in the relevant direction is less than one-sixth of the lowest wave encounter frequency. A transverse beam with attached force transducers was mounted on deck at $L_{p p} / 2$ and the connection point for the lines was at $[2.789, \pm 0.995,-0.448 \mathrm{~m}]$ model scale, relative to
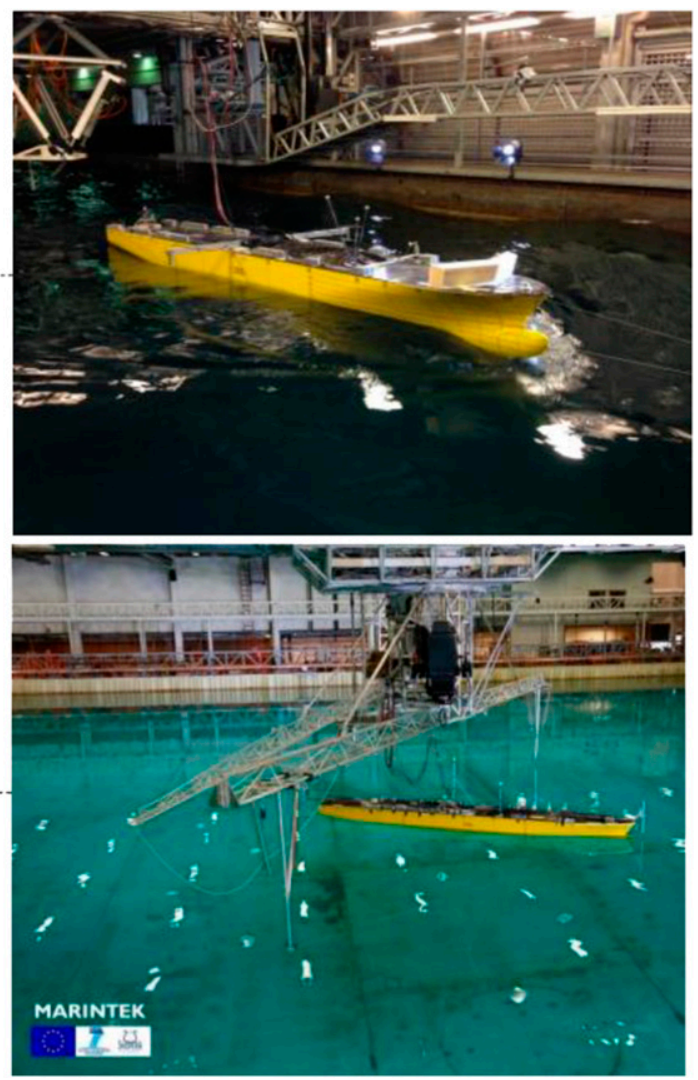

Fig. 3 DTC model in soft-mooring arrangement for added resistance (top) and drift force tests (bottom) at MARINTEK (left: schematic sketches, right: impressions from model tests) 
[After Perpendicular (AP), Center Line (CL), Base Line (BL)]. A supplementary set of force transducers was installed in the aft and fore joints of the lines to ensure consistency in the measurements.

For the drift force tests in deep water at MARINTEK, the DTC model was captive in a soft-mooring arrangement as visualized in Fig. 3 and held at position/towed by the gondola at constant speed. Lightweight lines were used and the spring stiffness has been chosen such that the eigenfrequency of the mooring in the relevant direction is less than one-sixth of the lowest wave encounter frequency. At the same time, the aim was to minimize the yaw drift angle (it was kept within $\pm 2^{\circ}$ ). A transverse beam was mounted to the gondola and the lines were deflected by low-friction pulleys to align and attach the springs vertically. Force transducers were mounted forward of the bow and behind the stern at CL and Height of Mass Center over Keel (KG). A supplementary set of force transducers was installed in the lines to ensure consistency in the measurements. The model was fitted with segmented bilge keels, rudder (fixed at $0^{\circ}$ rudder angle) and rudder box during this set of tests.

All wave environments have also been measured without the presence of the model for reference. For drift force tests, the gauge was located at the model position and for added resistance in a representative location between starting position and wave maker.

\subsection{Experimental setup KVLCC2, deep water}

To measure the mean drift forces in regular waves and deep water conditions at CEHIPAR, the model was restrained with a softmooring system consisting in four lines arranged in the shape of a diamond in the horizontal plane. The geometry of the system is given in Fig. 4 (left). Each line was made of a thin steel wire 3,780 mm in length. Two lines are attached to points a little forward of the bow and the other two were attached a little aft of the stern. The two lines at starboard are connected to one vertical pole fixed to the turret of the Computerized Planar Motion Carriage (CPMC), the two port ones are connected to a symmetric pole in the opposite side. The two poles are aligned with the midship section, which is slightly aft of the longitudinal Center of Gravity/Mass (COG). The points of connection of the lines with the model are at the same height as the COG to reduce the influence in rolling. The lines were almost horizontal. At each connection to the poles, a spring with a stiffness of $107 \mathrm{~N} / \mathrm{m}$ was attached.

The objective of the soft mooring is to be able to measure the drift forces while keeping the orientation of the model and influencing its motions the minimum possible. To this purpose, the mooring was designed such that the natural resonance periods in surge, sway, and yaw were well above the period of the largest wave to be tested. By motion decay tests, it has been confirmed that the natural periods for surge and sway are 7-17 times higher than the tested wave periods, whereas for yaw this ratio is between 3 and 6 .

The arrangement allows to easily change the orientation of the model with respect to the waves just by slowly rotating the turret of the CPMC.

The same arrangement was used for the added resistance tests in regular and irregular waves by moving the carriage at the desired speed. In this case, it was necessary to make the acceleration phase very smooth with very low acceleration to reduce the excitation of the soft-mooring resonances as much as possible.

The incoming wave has been measured by a wave probe forward of the model. This measurement is affected by the wave reflections from the model. The undisturbed reference wave height has also been measured in absence of the model. The vessel motions in 6 degrees of freedom (DOF) have been measured by an optical tracking system (Krypton). Wave forces have been measured by two six-component dynamometers, one at the bow and one at the stern at the points of attachment of the mooring lines. Additional load cells were mounted in each line.

Both the dynamometers and the load cells can be combined separately to give two different estimates of the surge and sway forces and the yaw moment so giving some redundancy. The results from the load cells gave similar results to those of the dynamometers except that they are slightly lower, probably due to friction at the pulleys used to connect the wires to the springs and load cells. All results presented in the following sections are direct measurements from the dynamometers.

\subsection{Experimental setup KVLCC2 and DTC, shallow water}

At FHR, captive model tests have been performed with a 1:75 scale model of the KVLCC2 and a 1:89.11 scale model of the DTC in the towing tank for Maneuvers in shallow water (cooperation with Ghent University, see Fig. 5 and Delefortrie et al. [2016] for more information). The usable dimensions of the tank are $68 \times 7 \times$ $0.5 \mathrm{~m}^{3}$. The KVLCC2 was tested at scantling and heavy ballast draught and the DTC at design loading condition (see Table 1).

The considered under keel clearances (UKCs) are expressed as a percentage of the draft at the aft perpendicular and have the following magnitude:

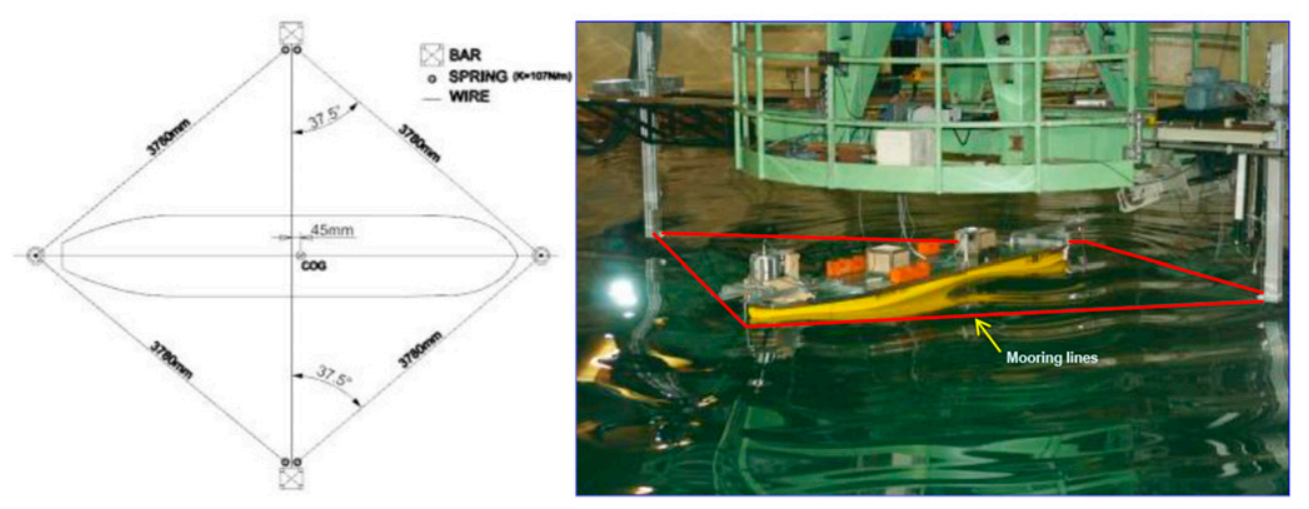

Fig. 4 Mooring arrangement for the drift force tests with the KLVCC2 model at CEHIPAR 

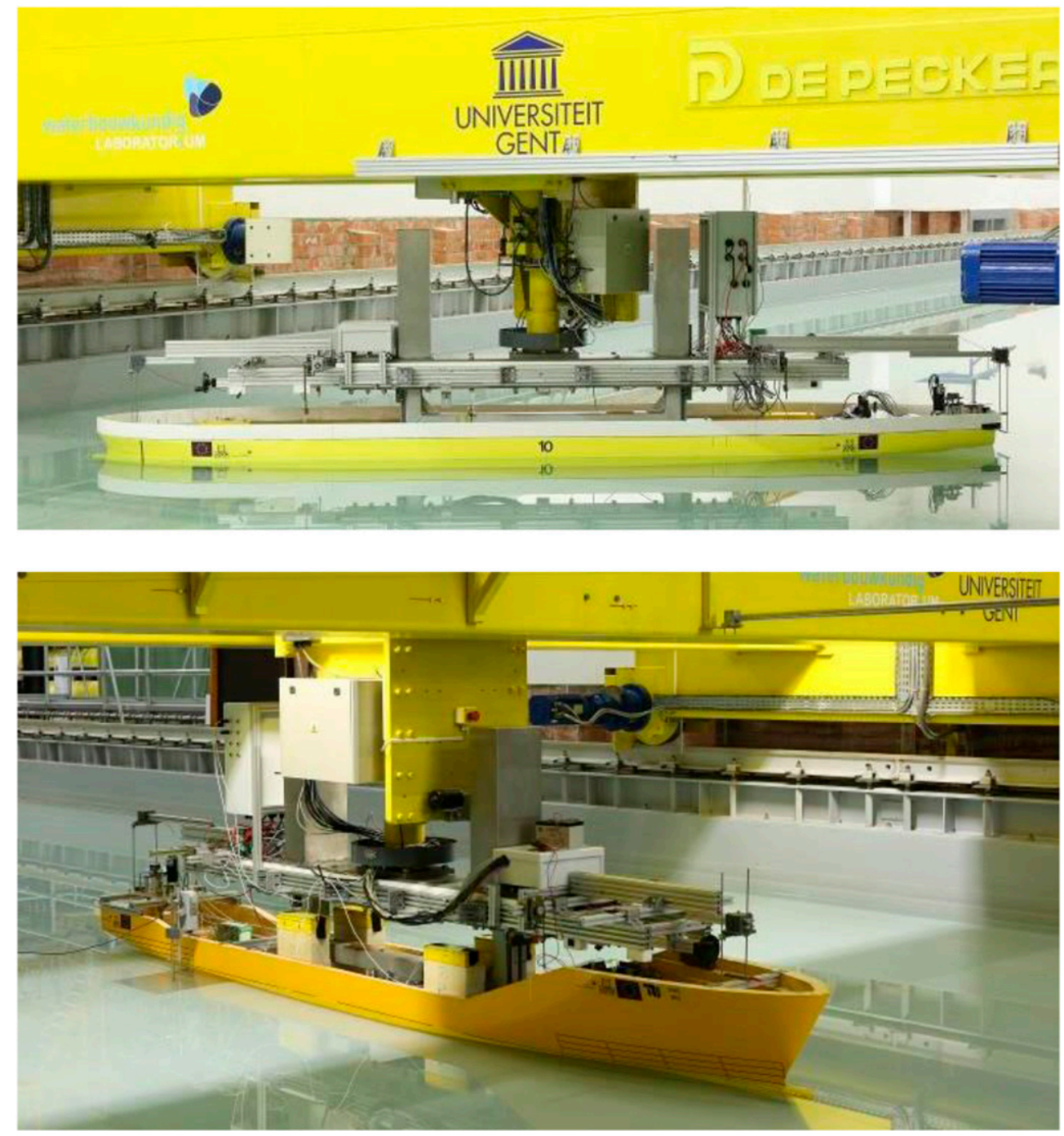

Fig. 5 Impressions of the KVLCC2 (top) and DTC model (bottom) in the captive test setup at FHR

- $30 \%$ and $20 \%$ for the KVLCC2, the latter only at scantling draft.

- $100 \%$ and $20 \%$ for the DTC.

The investigated Froude numbers (Fn) are 0, 0.055, and 0.11 for the KVLCC2, and 0, 0.052, and 0.139 for the DTC. At Fn $=0$, the drift angles were varied for the KVLCC2 (30\% UKC only) to investigate various incoming wave angles $\mu\left(180^{\circ}-30^{\circ}\right.$ in steps of $30^{\circ}$, which corresponds to the interval from head to stern quartering waves).
At FHR, the tests have been performed with fully restrained surge, sway, and yaw, whereas heave, roll, and pitch were free.

During the tests, the wave climate was measured at the four positions in the towing tank, as shown in Fig. 6.

Waves were varied in length between 0.2 and $1.2 \lambda / L_{p p}$. The resulting wave height is strongly dependent on the shallow water effects, which put a limit on the maximal wave height that can be tested. This topic was extensively discussed by Tello Ruiz et al. (2016). For the selected wave lengths, $50 \%$ and $70 \%$ of the wave heights listed in Table 2 were also tested.

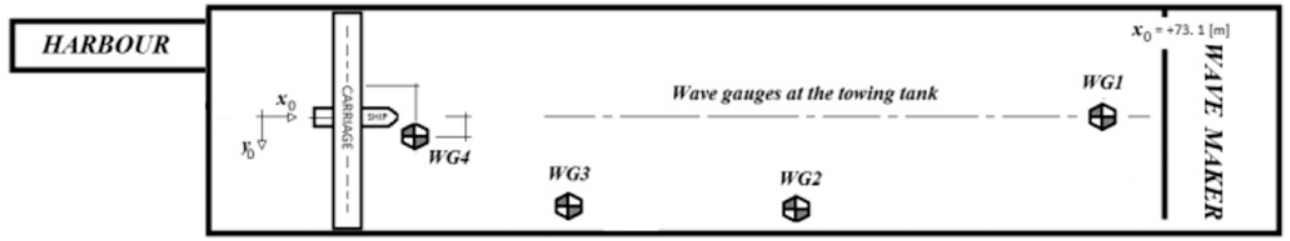

Fig. 6 Position of wave gauges in the towing tank at FHR 
Table 2 Base prototype wave heights at FHR

\begin{tabular}{lccc}
\hline Ship & UKC (\%) & Froude number & Wave height (m) \\
\hline KVLCC2-scantling & 30 & $0-0.11$ & 2.25 \\
& 20 & $0-0.11$ & 1.50 \\
KVLCC2-ballast & 30 & $0-0.11$ & 1.50 \\
DTC & 100 & $0-0.139$ & 5.00 \\
& 20 & $0-0.139$ & 2.00 \\
& & 0.139 & 1.20 \\
\hline
\end{tabular}

The raw results of all model tests are $40 \mathrm{~Hz}$ time series, which need some degree of postprocessing. Each test starts with a socalled calibration interval of about 10 seconds during which no further actions are performed to determine the offsets of each measurement channel. These offsets are then subtracted to obtain the net measurements.

The movement of the vessel in the vertical plane (heave, pitch, and roll) is measured using four gauges, which are connected to the fixed frame of the towing tank carriage. These four gauges are located at four fixed positions, which so enables to compute directly the ship's heave, pitch, and roll during the tests.

The force and moment components are also calculated based on the measurements of four separate force gauges. The total longitudinal X-force can be simply calculated as the sum of the fore and aft longitudinal force measurements. Similarly, the Y-force is obtained by addition of the fore and aft lateral force measurement. The yaw moment is calculated based on the longitudinal positions of the Y-force measurement gauges.

A useful time window is then determined based on the following constraints:

- Constraint 1: The velocity of the vessel is constant.

- Constraint 2: A fully developed regular wave system is present.

- Constraint 3: The transitional effects, which are present when the ship moves from calm water to waves, have disappeared.

- Constraint 4: The reflected waves (on ship model, tank wall and wave generator) have not yet reached the ship model.

Within this time window, a Fourier analysis is applied to determine the mean value $a_{0}$ and the harmonic coefficients $a_{1} \ldots a_{4}$ and $b_{1} \ldots b_{4}$ of each measurement:

$$
\begin{aligned}
f= & a_{0}+a_{1} \cdot \cos (\omega t)+b_{1} \cdot \sin (\omega t)+a_{2} \cdot \cos (2 \omega t)+b_{2} \cdot \sin (2 \omega t) \\
& +a_{3} \cdot \cos (3 \omega t)+b_{3} \cdot \sin (3 \omega t)+a_{4} \cdot \cos (4 \omega t)+b_{4} \cdot \sin (4 \omega t)
\end{aligned}
$$

The added resistance is then the $a_{0}$ value measured in a regular wave campaign minus the $a_{0}$ value measured in calm water for the same ship model sailing the same trajectory (straight line, same velocity).

\subsection{Experimental setup DTC, intermediate water depth}

Added resistance and drift force tests were performed in the seakeeping basin of TUB (at the former Berlin Model Basin VWS). Waves with height $H$ up to $0.30 \mathrm{~m}$ and frequencies $\omega$ from 0.5 to $12 \mathrm{rad} / \mathrm{sec}$ can be generated with the programmable wave generator (Fig. 7). Long-crested regular waves and irregular sea states with defined characteristics can be generated and reproduced very accurately in this facility.

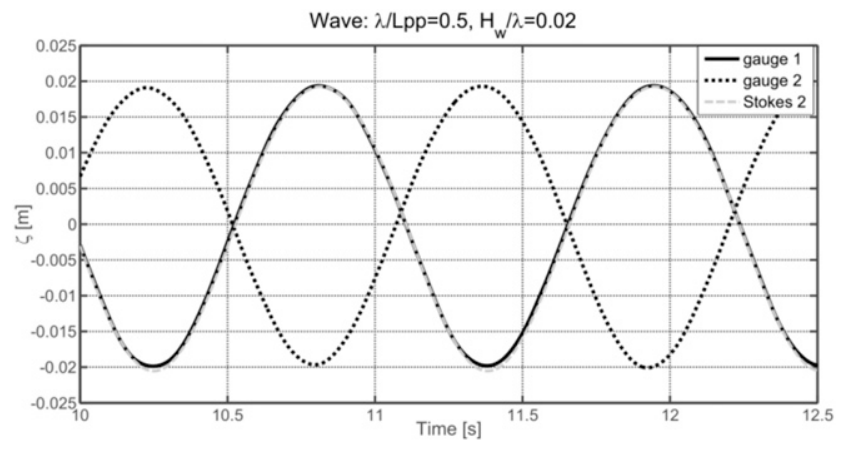

Fig. 7 Quality check of undisturbed wave $\lambda / L_{p p}=0.5$

The DTC model was tested at scale 1:89.11 at a water depth of $1 \mathrm{~m}$ leading to an UKC of $613 \%$ in the design condition. Note that due to the very slow forward speed considered, no shallow water effect was expected in calm water condition and the steady wave system. However, for incident waves longer than $2 \mathrm{~m}$, a certain influence of the bottom on the waves will be present due to the finite water depth.

During all performed model tests at TUB, the DTC model was equipped with segmented bilge keels and rudder. The propeller was not present. The model was built with an especially high freeboard so that large roll angles become possible without the necessity of a cover. This is important due to the used test setup described below.

The performed tests consisted in added resistance tests in regular head waves with two different model forward speeds corresponding to $\mathrm{Fn}=0.069$ and 0.139 and zero speed drift force tests, where mean forces and moments are measured. In the latter case, the incident wave angle was varied in $30^{\circ}$ steps from head to following seas in order to obtain wave forces from all directions for maneuvering prediction purposes. A total of seven wave lengths ranging between 0.35 and $1.2 \lambda / L_{p p}$ were selected for all testing conditions. The wave steepness was kept constant at $H / \lambda=0.02$ for all waves. Note that for this steepness, the Airy (linear wave) theory is not completely valid any more (see Clauss et al. 1992). To investigate the influence of the wave steepness, two additional tests with a modified wave amplitude were performed in each condition for the shortest wave and for the wave length leading to the maximum RAO value of the most relevant force involved.

In order to ensure the wave quality in the tank and confirm the desired wave parameters, all waves were measured previous to the tests in the seakeeping basin without the model or any other obstacle. For this purpose, three wave gauges (P1, P2, and P3) were installed at $40,48.15$, and $50 \mathrm{~m}$ from the wave generator, the ship target location being $49 \mathrm{~m}$. The measured free surface elevation in the tank for an exemplary test wave (No. $3, \lambda / L_{p p}=0.5$ ) at gauges $\mathrm{P} 1$ and $\mathrm{P} 2$ is shown in Fig. 7 compared to a theoretical wave calculated according to the second-order Stokes theory (dashed grey curve). The agreement between measured and theoretical free surface elevation is very satisfactory. The maximal relative errors for all waves considered were about $2 \%$ in amplitude (worst for the longest waves) and $0.2 \%$ in length (worst for the shortest wave).

In the scope of this research project, a new measurement platform has been developed at TUB, especially designed to determine hydrodynamic forces and moments acting on a ship model in waves. Thereby, the 6 DOF motions of the model are measured as well. The new device, shown in Fig. 8, has been designed such that the model 

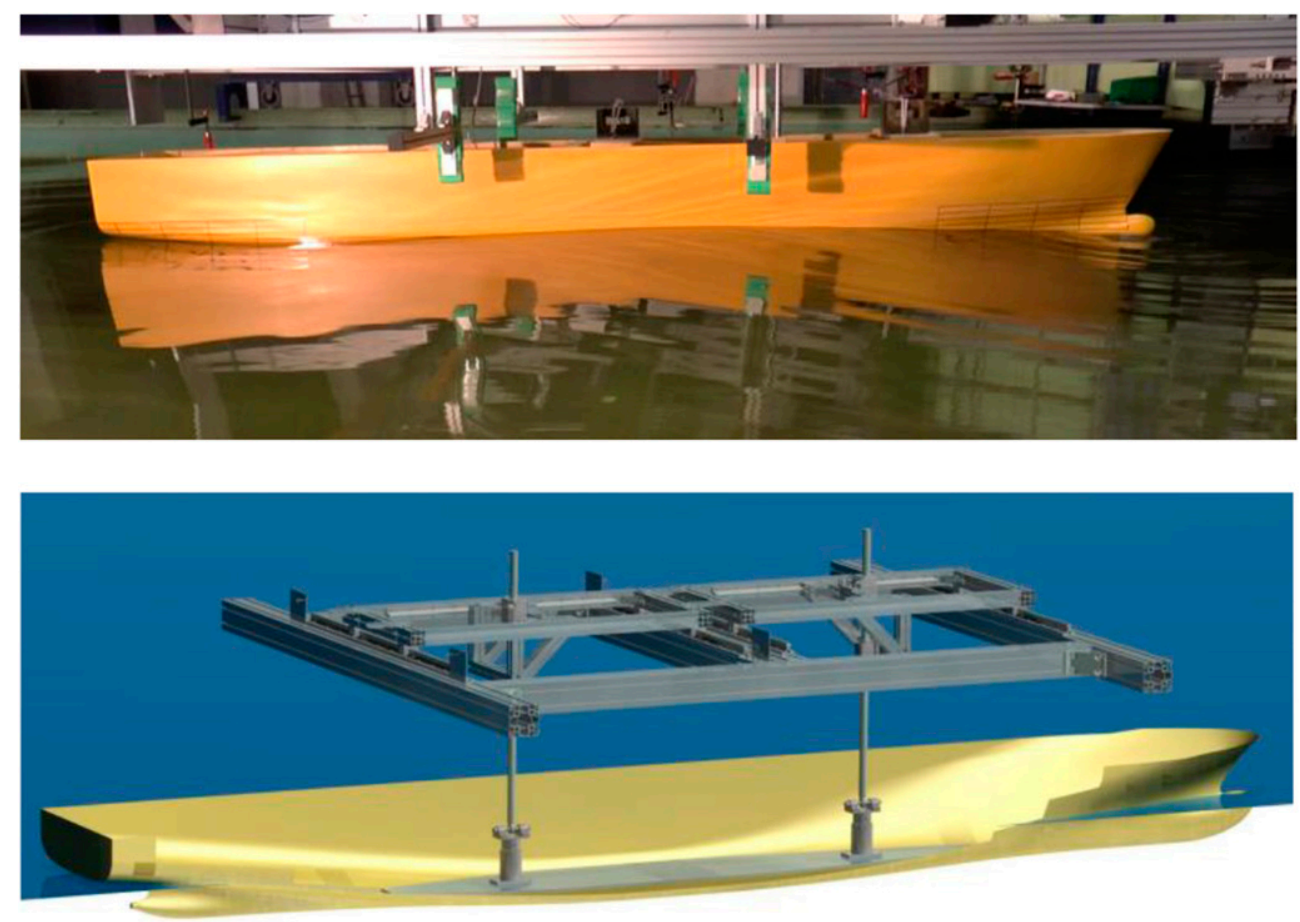

Fig. 8 Measurement platform developed and used for added resistance and drift force tests at TUB

motions are constrained as few as possible in order to minimize influences on the registered time traces and mean values of forces and moments. Xu et al. (2007) used an arrangement of similar type to perform PMM tests in waves.

The measurement platform is coupled with the towing carriage and consists of two nested slides (front and back). Each slide consists of a $\Delta y$-slide for transversal motion and a nested $\Delta x$-slide for longitudinal motion, both displacing with low-friction linear ball bearings on steel rails. The slides are softly held at a mean position by springs connected to each slide. Table 3 shows the resulting total stiffness of the springs for the different motion directions.

Because of the motions of the slides, the model can move in the horizontal plane, only restricted by spring stiffness and a maximum motion amplitude of each slide of $0.2 \mathrm{~m}$. Each $\Delta \mathrm{x}-$ slide has a vertical "heave rod" connected to the model via a rod end to allow free heave, roll, and pitch motions (see Fig. 9). Between each rod end and the model, a force gauge is placed to measure the forces at these two points. With these measured forces and knowing the position of the force gauges, the global longitudinal and transversal force on the model in ship fixed coordinates as well as the yaw moment are obtained. If the pure hydrodynamic forces are sought, i.e., for direct comparison with

Table 3 Spring stiffness of the test setup for drift forces and added resistance test with the DTC model at TUB

$$
\frac{\mathrm{C}_{\chi}[\mathrm{N} / \mathrm{m}]}{373.6} \quad \frac{\mathrm{C}_{\chi}[\mathrm{N} / \mathrm{m}]}{792.0} \quad \frac{\mathrm{C}_{\psi}\left[\mathrm{Nm} /{ }^{\circ}\right]}{5.4}
$$

CFD results, they can be obtained from these forces after deduction of weight and inertial force contributions in the respective direction. The inertial contributions can be quite large, especially for wave lengths causing large model motions, and therefore the pure hydrodynamic mean forces can deviate considerably from those including inertial effects as shown in Fig. 10 for the added resistance.

The model motions are measured with a set of 10 cable actuated distance sensors with low friction. This redundant arrangement has been chosen for minimum motion interference. With the signals of

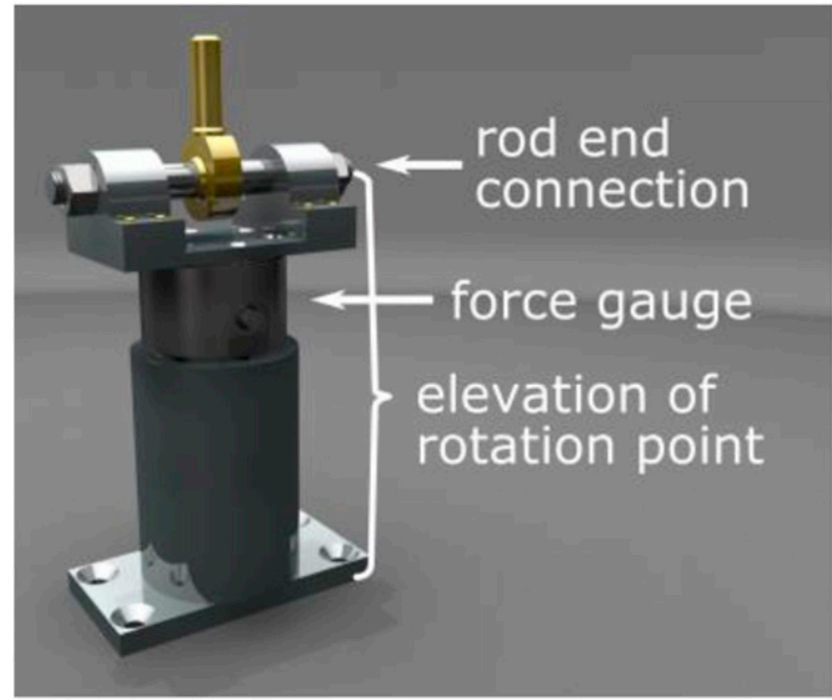

Fig. 9 Force gauge setup at TUB 


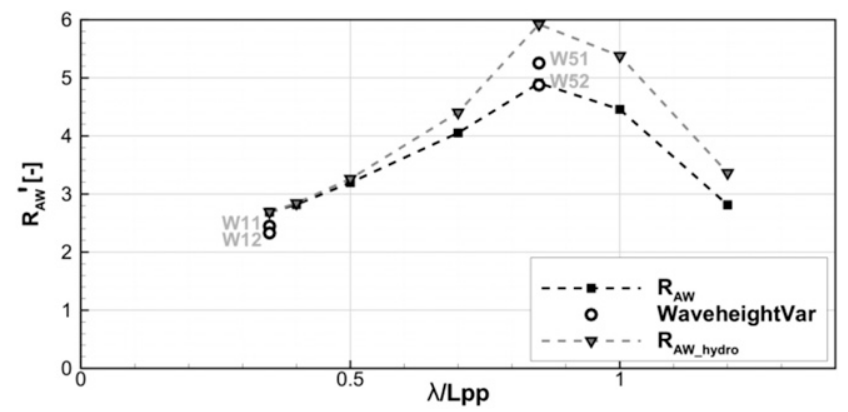

Fig. 10 Measured added resistance for the DTC at Fn $=0.139$ in head seas (TUB)

six distance sensors, the motion parameters can be determined in real time during the tests allowing for an accurate calculation of all inertial contributions.

\subsection{Selected results DTC}

The added resistance of the DTC hull has been measured in a range of $0.1 \leq \lambda / L_{p p} \leq 1.2$. The choice of force sensors was a delicate procedure since they had to be watertight, lightweight, and cover a wide range of force amplitudes with sufficient accuracy.

The shortest waves were measured at MARINTEK, with the wave maker operating at its lower limit and the wave time series reveal that the waves were not as stable as for the other tested wave periods.

Although the measured total longitudinal forces are very similar for the three investigated wave heights at $\lambda / L_{p p}=0.1$, the RAO data are scattered. This is caused by the normalization with very small denominator values (squared wave amplitudes) that amplify the uncertainties of the experimental data in this range. Because of these uncertainties, these data are not presented in the following graphs. However, there is an observed tendency that the RAO values for the added resistance increase for shorter relative wave lengths. Note that this range is of particular interest for large vessels since it covers quite frequent operating sea states (e.g., for the DTC, $\lambda / L_{p p}=0.2$ corresponds to a wave length of $70 \mathrm{~m}$ or a wave period of 6.7 seconds in deep water).

Three different water depths, UKC, and wave steepnesses were considered for the added resistance tests with the DTC hull at design draught and Fn 0.052 and 0.139.

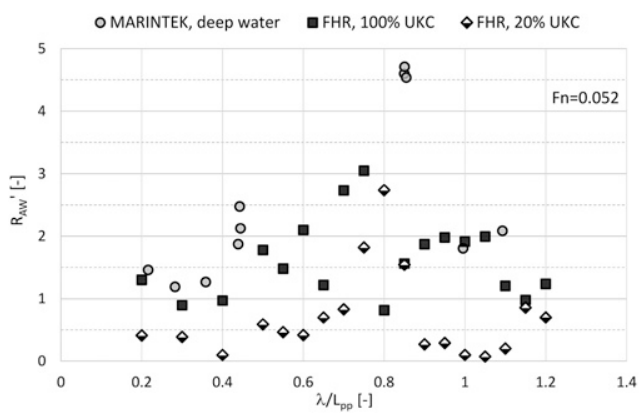

For Fn 0.052, the measured normalized added resistance values $R_{\mathrm{AW}}^{\prime}$ (nondimensionalized with the square of the incident wave amplitude, equation [2]) are increasing with increasing water depth and UKC (see Fig. 11, left). Although the magnitudes of the $R_{\mathrm{AW}}^{\prime}$ RAOs are different, the overall tendencies are similar, with the peak of the RAOs being located around $\lambda / L_{p p}=0.8$.

For Fn 0.139, as presented in Fig. 11 (right), the normalized added resistance RAO values for deep water (636.5-m water depth at full scale), intermediate water depth (89.11-m water depth at full scale), and the $100 \%$ UKC condition (29.0-m water depth at full scale) are also quite similar in the tendency. Here the normalized added resistance at $20 \%$ UKC (17.4-m water depth at full scale) is significantly higher for all investigated wave conditions, indicating a stronger shallow water effect on the steady wave system. However, looking at the actual dimensionalized forces presented in full scale in Fig. 12, it becomes evident that the values measured for $20 \%$ UKC are still the smallest in view of the associated small incident wave heights that were used for the normalization.

Actually, there are several counteracting, partly enhancing, and partly diminishing effects that lead to the high normalized values as shown in Fig. 11, noting that the static UKC for these runs is $20 \%$ (or merely $3.25 \mathrm{~cm}$ at model scale). The sinkage measurements in these runs revealed squat effects leading to a dynamic UKC of only $10.7 \%$ (or $1.75 \mathrm{~cm}$ ) in calm water and of merely $0.9 \%$ (or $0.15 \mathrm{~cm}$ ) in the presence of waves. This is certainly an extreme condition, where the vessel is sailing in the boundary layer of the bottom flow of the towing tank, which is herein estimated to be 7.6-cm-thick, according to Prandtl's law. The effect of this on the added resistance is not yet known and needs to be reassessed.

Because of the very low tested UKC, the wave amplitudes had to be very small $(0.6 \mathrm{~m}$ full scale, or $6.7 \mathrm{~mm}$ at model scale $)$ in order to avoid that the heave and pitch motions cause bottom contact of the ship model. For such small wave amplitudes, measurements and accuracies are challenged. The different measured force levels in Fig. 12 are resulting from the different wave amplitudes (steepness) used in the tests. At $\lambda / L_{p p}=1$, the full-scale wave amplitudes used by MARINTEK (light gray circles) are $6.25,4.7$, and $3.1 \mathrm{~m}$. The full-scale amplitude at TUB is $3.1 \mathrm{~m}$ (black and white triangles) and at FHR is $2.5(100 \%$ UKC, black squares) and $0.55 \mathrm{~m}(20 \%$ UKC, black and white diamonds). Note that measured force values by different facilities (MARINTEK and TUB) but for the same conditions, namely for $\lambda / L_{p p}=1$ and wave amplitude $3.1 \mathrm{~m}$, are very similar, while

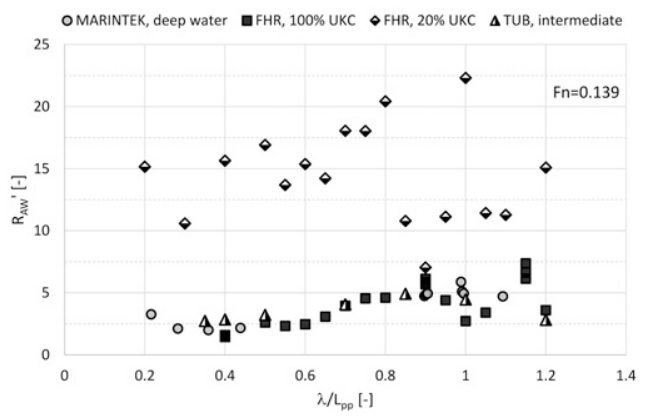

Fig. 11 Comparison of normalized added resistance data measured with the DTC model at design draught at Fn $=0.052$ (left) and Fn $=0.139$ (right) in different water depths, head waves 


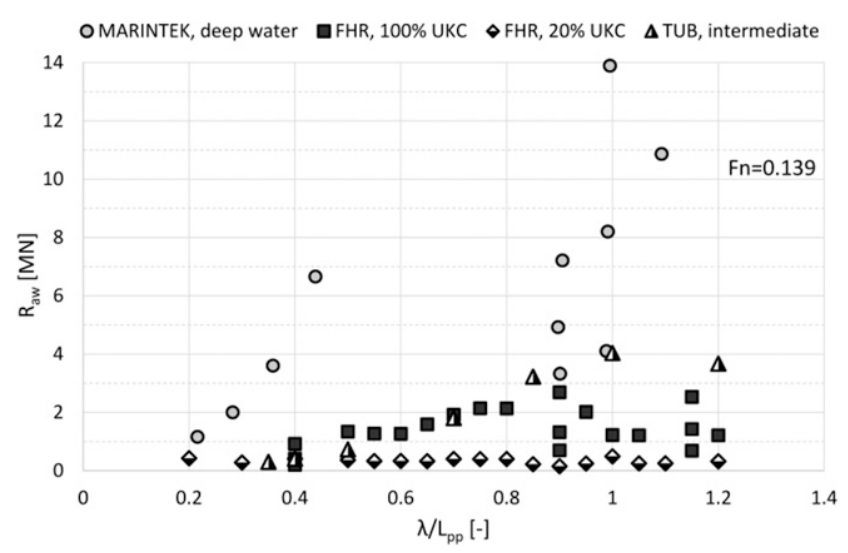

Fig. 12 Full scale added resistance for the DTC model at design draught at $\mathrm{Fn}=0.139$ in different water depths, head waves

measured forces for different amplitudes are clearly increasing with the squared amplitude of the wave.

Further added resistance tests with a lighter loading condition for the DTC (light ballast, Table 1) were performed at TUB for $\mathrm{Fn}=0.069$ and $\mathrm{Fn}=0.139$. As expected, the nondimensional added resistance increases with increasing forward speed, accompanied by a shift of the peak toward longer waves (see Fig. 13).

Systematic experimental data for the added resistance in oblique seas are not easily available. Series of tests with the DTC at design loading condition were performed at MARINTEK, with varying encounter angle from head $\left(180^{\circ}\right)$ to following seas $\left(0^{\circ}\right)$ in $30^{\circ}$ intervals. The results are summarized in Fig. 14. The highest forces were measured in head seas and bow quartering seas (waves $120^{\circ}$ off the bow), whereas the peak of the RAOs is shifting toward shorter waves in off head encounter wave conditions. In shorter waves, i.e., $\lambda / L_{p p}<0.3$, the added resistance is similar for headings from $180^{\circ}$ to $120^{\circ}$. At $60^{\circ}$, the measured added resistance is small, changing sign at $\lambda / L_{p p}=0.25$. From $30^{\circ}$ to $0^{\circ}$ (stern quartering to following seas), the added resistance becomes negative, i.e., the vessel experiences a pushing effect rather than a resistance caused by the presence of the waves. Note that due to the absolute size of the DTC, namely $L=355 \mathrm{~m}$, the most common waves that this ship may encounter in practice are in the relative "short waves" region.

The presentation of experimental data for the DTC is herein not (and cannot be) exhaustive, but rather provides some examples, where it is interesting to compare data from different laboratories or testing conditions.

The measured time traces of motions and forces obtained with the new measuring device at TUB were evaluated carefully to obtain force and motion RAOs for the DTC. An exemplary time trace of the model motions with respect to the ship fixed origin at $\left[L_{p p} / 2, \mathrm{CL}\right.$, WL] for a test with $F n=0, \lambda / L_{p p}=0.85$ and $\mu=150^{\circ}$ (test No. 107, design draught) is shown in Fig. 15. As can be seen, the model could move freely in all 6 DOF. The time traces of surge, sway, and yaw motions show nonzero mean values, stemming from the mean second order forces.

The measured time traces of longitudinal and transversal forces for test No. 107 are shown in Fig. 16, showing force amplitudes of about 4 and $6 \mathrm{~N}$, respectively. The corresponding mean force values of -0.66 and $-1.05 \mathrm{~N}$ (dotted lines) are substantially smaller. This exemplifies the essential difficulty of this kind of tests: a sought

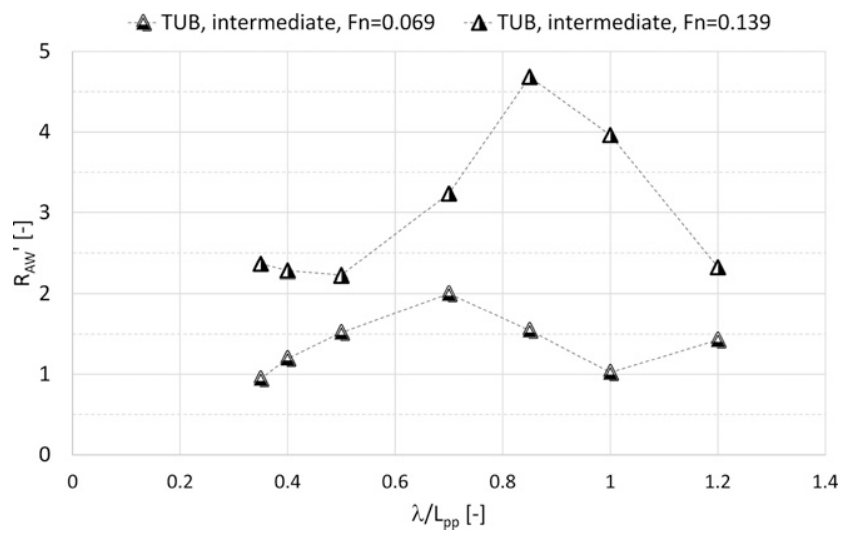

Fig. 13 Comparison of added resistance data measured with the DTC model at light ballast draught at $\mathrm{Fn}=0.069$ and $\mathrm{Fn}=0.139$ in intermediate water depth, head waves

rather small mean value obtained by averaging oscillations with high amplitude. During data postprocessing, mean values are generated by averaging over a time span comprising at least 10 oscillation periods obtained from the complete time traces.

The results for the added resistance at $\mathrm{Fn}=0.139$ in head waves and a wave steepness $H / \lambda=0.02$ are shown in Fig. 10 (black squares with dashed curve). This force RAO has a peak at about $\lambda / L_{p p}=0.85$ and decreases toward longer waves. The variation of the wave amplitude (open circles in Fig. 10) shows that the normalized added resistance varies slightly, decreasing for larger wave steepness. It is noted that for the wave length $\lambda / L_{p p}=0.85$, the steepness of waves W51 and W52 was 0.014 and 0.026, respectively, whereas for the shortest wave length $\lambda / L_{p p}=0.35$, the steepness of waves $\mathrm{W} 11$ and $\mathrm{W} 12$ was 0.029 and 0.037 , respectively. In addition, the pure hydrodynamic mean force from tests with constant steepness (triangles with light gray dashed line in Fig. 10) is shown, which is up to $20 \%$ larger than the measured force (including inertial effects) for wave lengths above $\lambda / L_{p p}=0.6$, the region where ship motions become large.

Finally, Fig. 17 shows the nondimensional longitudinal and transversal mean forces, as well as the mean yaw moment, measured for all considered encountering angles and wave lengths for the

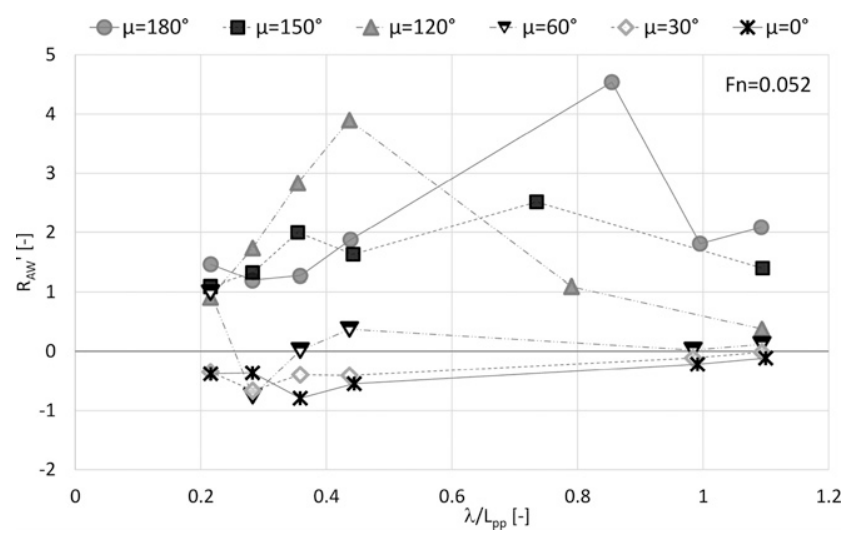

Fig. 14 Comparison of added resistance data measured with the DTC model at design draught and $\mathrm{Fn}=0.052$ in deep water and different wave headings $\left(180^{\circ}\right.$ denotes head seas) 

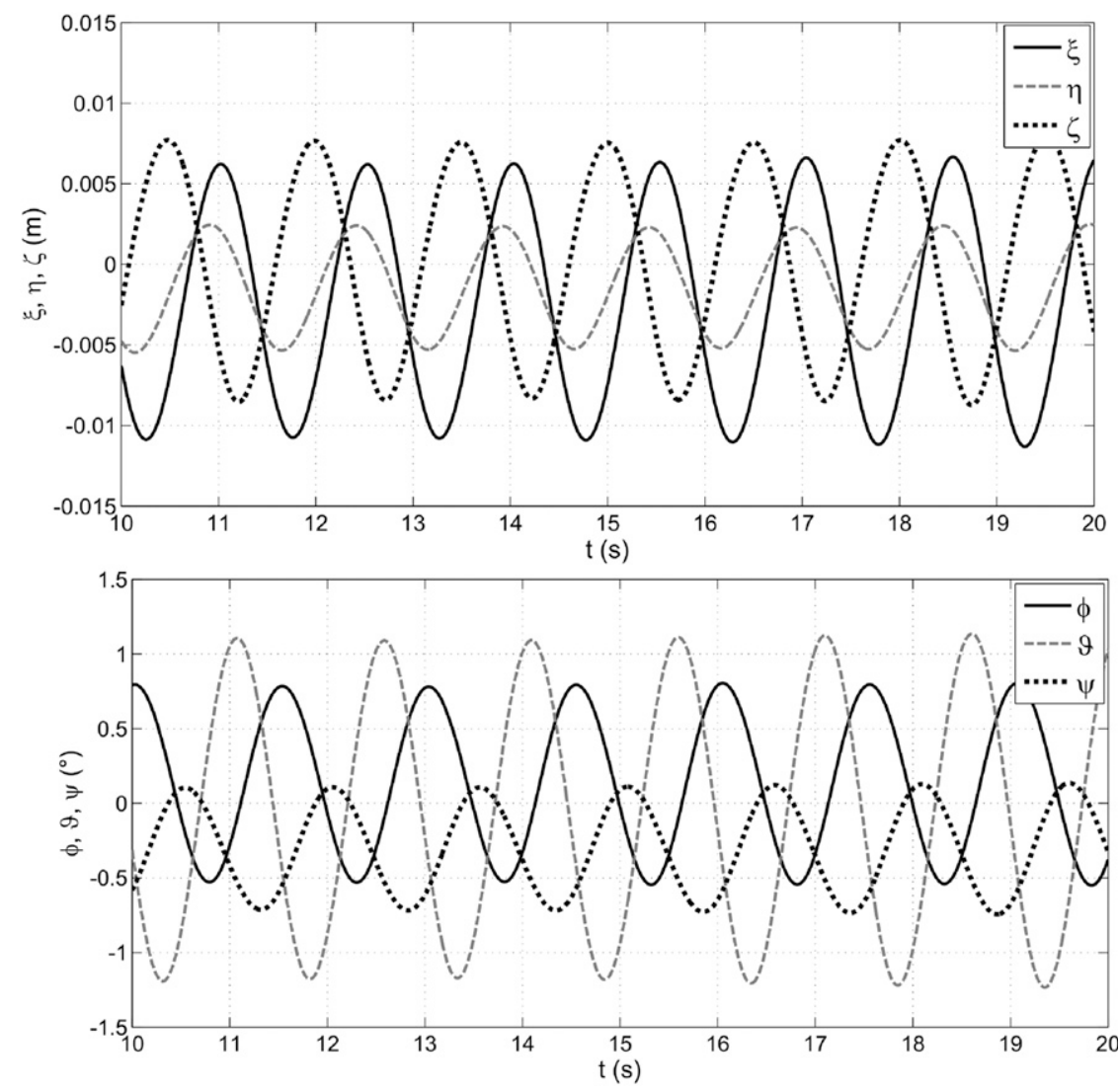

Fig. 15 Measured model motions during the wave force test with $\mathrm{Fn}=0, \lambda / L_{p p}=0.85$ and $\mu=150^{\circ}$, DTC test No. 107

DTC at zero speed. In the diagrams especially short wave phenomena are noticeable, e.g., the longitudinal force $F_{X}$ ' at $\mu=90^{\circ}$ has a significant negative value for wave lengths up to $\lambda / L_{p p}=0.4$, whereas wave lengths above $\lambda / L_{p p}=0.5$ yield almost no mean value. Also for the yaw moment $\mathrm{M}_{\mathrm{Z}}$, the short waves generate a mean moment at $\mu=90^{\circ}$ and the zero-crossing angle is shifted towards $\mu>100^{\circ}$. As known from numerous studies on this topic, the nondimensional side forces reveal the largest values in short waves and decrease in longer waves. This tendency is clearly visible in Fig. 18. Note that during a large number of tests, the DTC experienced stern slamming (pounding), even in very short bow quartering waves of moderate steepness. This may lead to an additional increase of the nondimensional side forces in short waves.

\subsection{Selected results KVLCC2}

For the added resistance tests with the KVLCC2 at scantling draught, three different water depths and UKCs were considered.

In Fig. 18 (top), the measured normalized added resistance values for $\mathrm{Fn}=0.055$ in head waves are shown. A similar tendency as for the DTC results can be observed: the RAO values are increasing with increasing water depth and UKC in the in the range $0.2 \leq$ $\lambda / L_{p p} \leq 0.65$, while trends reverse for longer waves $\left(\lambda / L_{p p}>1.1\right)$, where shallow water effects are expected to increase. In shallow water conditions, the peak of the RAO is located around $\lambda / L_{p p}=$ 0.8 , whereas it appears to be close to $\lambda / L_{p p}=0.65$ in deep water. For the Fn $=0.11$ case, as presented in Fig. 18 (bottom), the added resistance RAO values for deep water (400-m water depth at full scale) and 30\% UKC condition (27.0-m water depth at full scale) are very similar in the range $0.3 \leq \lambda / L_{p p} \leq 0.8$. The lowest added resistance values are obtained for the $20 \%$ UKC condition $(25.0-\mathrm{m}$ water depth at full scale, diamond shapes) in short waves, whereas some peak is noted for $\lambda / L_{p p}=0.9$.

The above tendencies are the result of series of factors, such as ship size and magnitude of the wave-induced motions in response to the incoming waves, the effect of finite water depth on the steady and incoming unsteady wave system, the interaction between steady and unsteady wave system, the viscous effects of the tank bottom

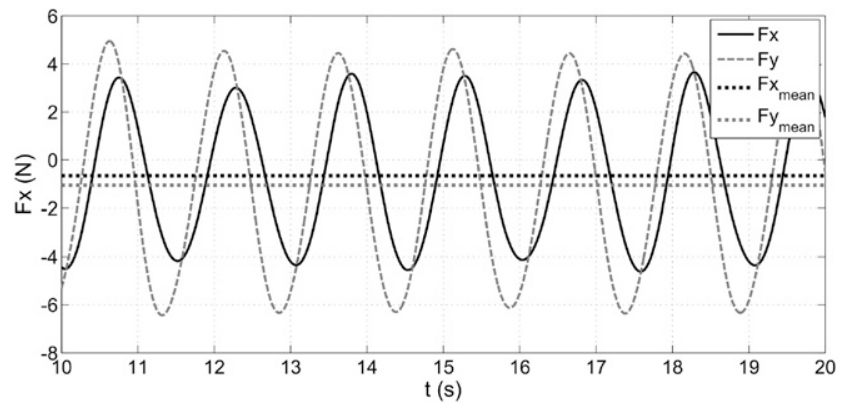

Fig. 16 Measured forces during a wave force test at zero speed with $\lambda / L_{p p}=0.85$ and $\mu=150^{\circ}$, test No. 107 (TUB) 

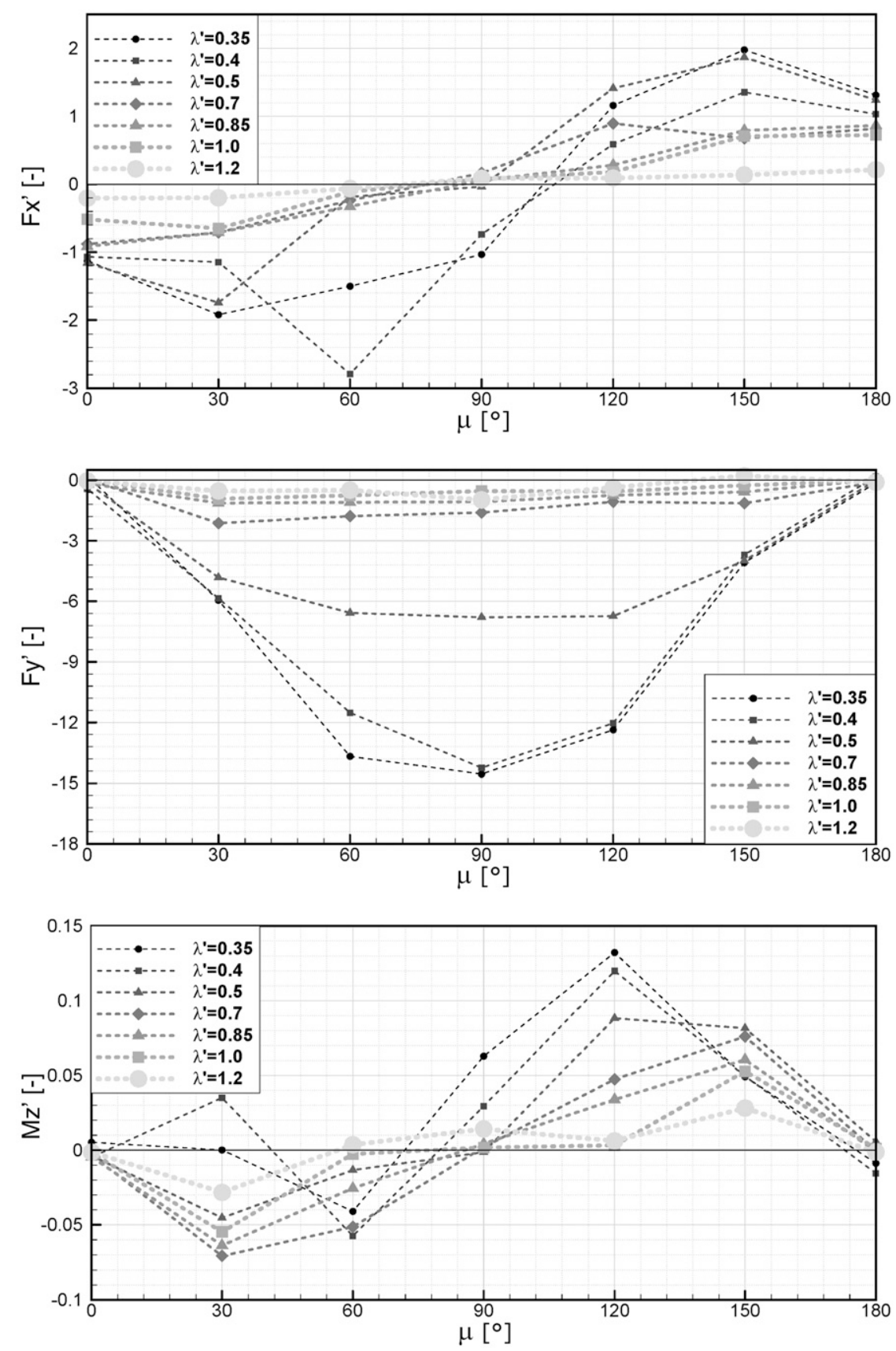

Fig. 17 Wave induced mean longitudinal force, transversal force and yaw moment (from top to bottom) for the DTC at zero speed for all wave lengths and encountering angles (TUB)

boundary layer for the small UKC conditions, and uncertainties related to the smallness of the generated waves for some test conditions.

Another focus of the experimental program of the SHOPERA project was on the measurement of wave-induced drift forces (zero speed problem) in regular waves for the KVLCC2. Numerous drift force tests have been conducted both in deep water at CEHIPAR and in shallow water conditions at FHR.

An example of the results is presented in Fig. 19, where the longitudinal drift forces (top), lateral drift forces (center), and yaw drift moments (bottom) of the KVLCC2 at scantling draught for $\mu=150^{\circ}$ and $\mathrm{Fn}=0$ are compared. The tendencies for the longitudinal forces are similar to that for the added resistance results: the RAO values for deep water (400-m water depth at full scale, black $\mathrm{X})$ and $30 \%$ UKC condition (27.0-m water depth at full scale, black squares) show the same trend in the range $0.3 \leq \lambda / L_{p p} \leq 0.8$, as in Fig. 19 for the added resistance. For longer waves, the forces in shallow water are increasing toward a peak around $\lambda / L_{p p}=0.9$, whereas they are decreasing in deep water condition. The normalized lateral forces for both water depths are very similar for $\lambda / L_{p p} \geq 0.4$. For shorter waves, the RAO values for the lateral forces in deep water are enhanced, while they are almost constant in shallow water. The yaw drift moment behaves similarly at both 

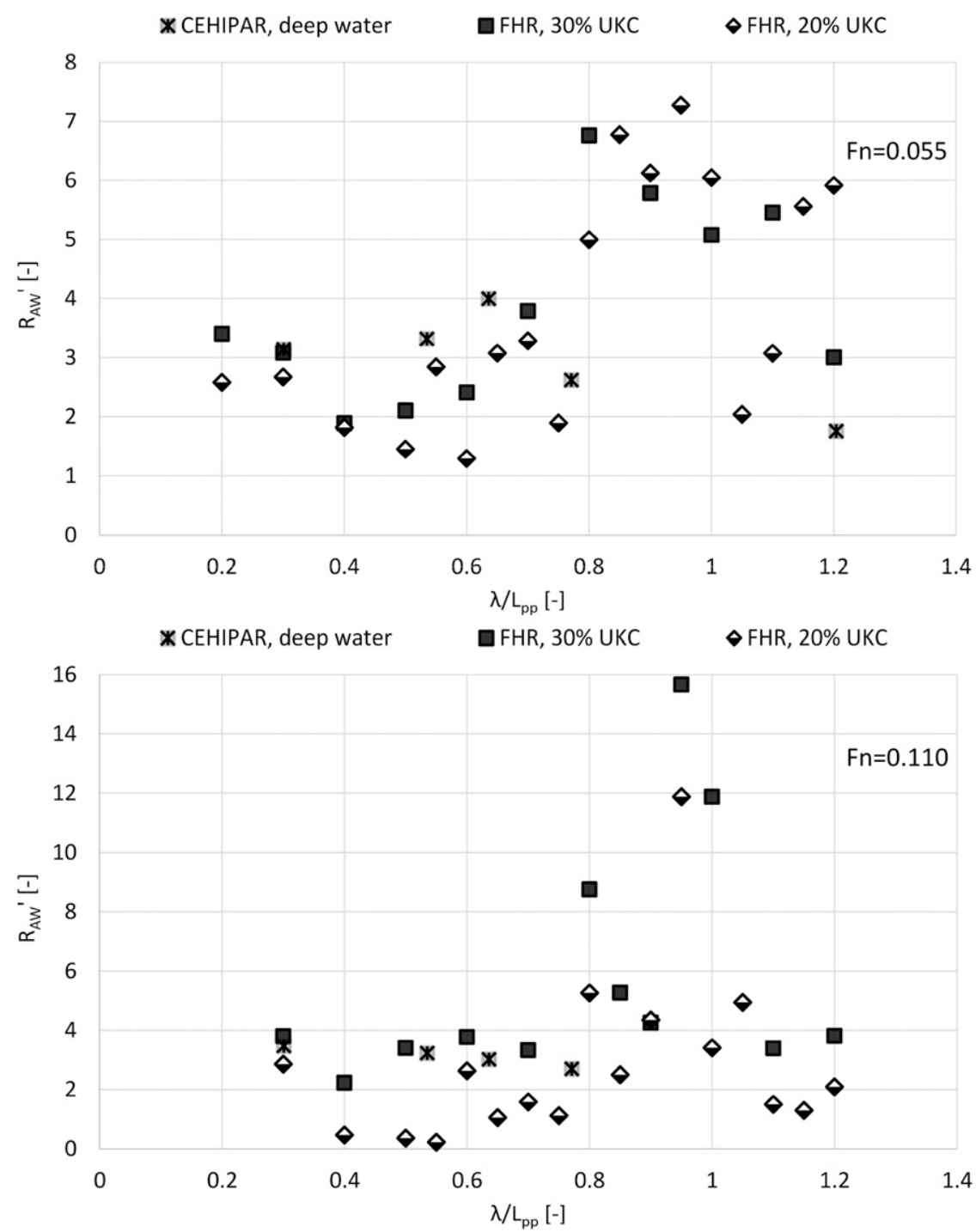

Fig. 18 Comparison of added resistance data measured with the KVLCC2 model at scantling draught at Fn $=0.055$ (top) and Fn $=0.11$ (bottom) in different water depths, head waves

water depths, while changing sign in the region $0.3 \leq \lambda / L_{p p} \leq 0.6$. The magnitude of moments in shallow water is generally larger than in deep water condition. Note, however, that the results for $30 \%$ UKC were obtained with a 3 DOF test setup (FHR) and the deep water results with a $6 \mathrm{DOF}$ arrangement (CEHIPAR). Although the $6 \mathrm{DOF}$ setup leaves surge, sway, and yaw restrained in a softmooring arrangement, the $3 \mathrm{DOF}$ setup fully constrains the horizontal degrees of freedom (see Tello Ruiz et al. 2015). Both setups are commonly treated as equivalent in head sea conditions (ITTC 2011), but the different nature of the two setups clearly affects the mean drift forces in oblique seas, especially due to the constraint of sway and yaw in the 3DOF setup. Thus, some caution is necessary when assessing these results. However, since experimental data on added resistance and drift force in oblique seas are rare, the results presented in Fig. 19 appear important enough to be published despite the limited comparability between the deep and shallow water condition.

The presentation of experimental data for the KVLCC2 is herein not (and cannot be) exhaustive but rather provides typical comparative examples for data from different laboratories and/or testing conditions.

\section{Propulsion and rudder force tests}

In order to obtain insight into the effect of waves on rudder forces and propulsion characteristics, the SHOPERA test program contains a set of propulsion and rudder force tests in calm water and waves for both the DTC and the KVLCC2 hull.

For data comparison purposes, the following nondimensional properties were used for the rudder forces and moments in bollard pull condition $(\mathrm{Fn}=0)$ :

$$
F_{\mathrm{R} b}^{\prime}=\frac{F_{\mathrm{R} b}}{\frac{\rho}{2} v_{0.7}^{2} A_{\mathrm{R}}} \quad M_{R L}^{\prime}=\frac{M_{\mathrm{R} b}}{\frac{\rho}{2} v_{0.7}^{2} A_{\mathrm{R}} c}
$$

where $v_{0.7}=2 \pi n r_{0.7}$ is the characteristic propeller rotational speed, $c$ is the chord length at half rudder height, and $A_{\mathrm{R}}$ is the total rudder area. 

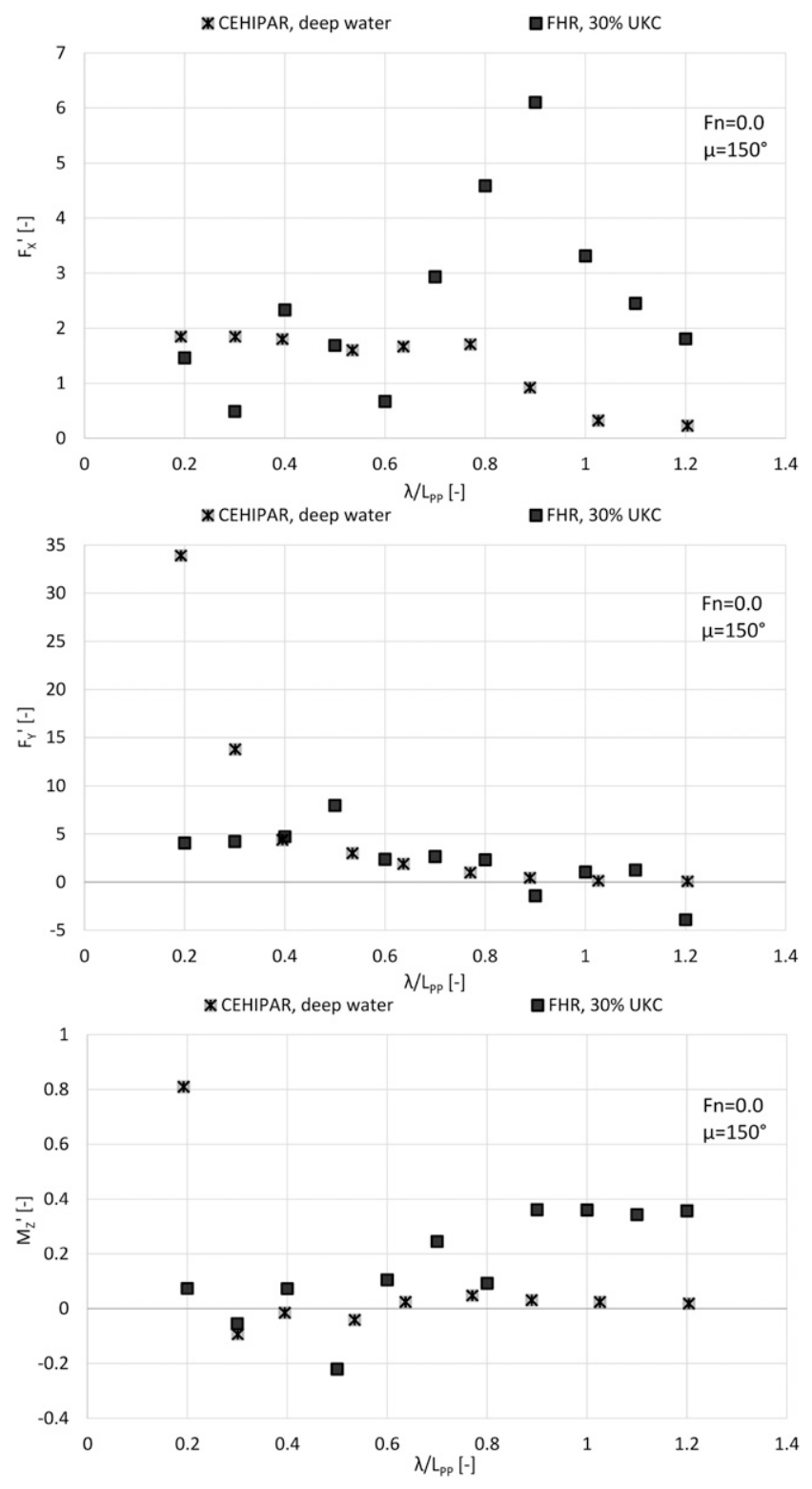

Fig. 19 Comparison of measured longitudinal drift forces (top), lateral drift forces (center) and yaw drift moments (bottom) for the KVLCC2 model at scantling draught and in different water depths

Rudder forces at forward speed are nondimensionalized as follows:

$$
F_{\mathrm{R}}^{\prime}=\frac{F_{\mathrm{R}}}{\frac{\rho}{2} v_{\mathrm{s}}^{2} A_{\mathrm{R}}}
$$

where $v_{\mathrm{s}}$ is the ship forward speed. Thrust and torque are expressed as coefficients:

$$
K T=\frac{T}{\rho n^{2} D^{4}} \quad 10 K Q=10 \frac{Q}{\rho n^{2} D^{5}}
$$

\subsection{Experimental setup DTC}

The propulsion and rudder force tests in head waves have been performed with mean speeds corresponding to $\mathrm{Fn}=0.052$ and
0.087 , respectively. In order to find the respective propeller revolution settings for each wave condition, an iterative procedure was used, where one slightly higher and one slightly lower speed was run and the final settings were determined by linear interpolation.

For the propulsion tests, the model was free running and controlled by MARINTEK's online autopilot software NEMO, with an applied rudder rate of $25.0 \% \mathrm{sec}$ model scale (corresponding to $3.0 \% \mathrm{sec}$ full scale). The online proportionalderivative (PD) regulator of the autopilot software has been tuned to find the optimum settings (constant revolutions per minute [rpm] approach) for the tests. The instrumentation consists of a rudder servo for the autopilot, a dynamometer to measure thrust, torque, and $\mathrm{rpm}$, the optoelectronic position measuring system OQUS for measurement of motions in $6 \mathrm{DOF}$ and four conductive wave tapes to measure the relative waves elevation at the port side fore shoulder of the hull. During the propulsion tests, thrust, torque, rpm, forward speed, vessel motions in 6DOF, relative wave elevations at the portside fore shoulder, as well as rudder angle and rudder forces and rudder stock moments have been measured. Prior to the propulsion tests, open water tests with the DTC propeller have been performed in the towing tank.

Calm water bollard pull and rudder force tests were performed for three different propeller revolution settings in MARINTEK's Ocean Basin. The model was moored at the stern at deck height ( $[-0.106,0.0,0.474]$ model scale, from [AP, CL, BL]) and free in sinkage and trim. The rudder angle has been gradually increased in $5^{\circ}$ steps toward starboard, with a measuring time of at least 30 seconds per rudder angle. Rudder forces and the rudder stock moment have been measured in ship-fixed coordinates by sensors in the rudder stock. A positive rudder angle denotes that the rudder is set toward portside.

All wave environments were measured beforehand without the presence of the model for reference.

\subsection{Experimental setup KVLCC2}

During rudder force tests, the model was self-propelled and partially captive, connected to the Computerized Planar Motion Carriage (CPMC) by means of a six-component dynamometer assembled with bars. Each bar was joined to the model by means of a knuckle joint allowing the roll, pitch, and heave motions; while yaw, surge, and sway remain restrained. The roll axis was parallel to the base line and passing through the center of gravity of the model. The model was also equipped with a rudder dynamometer. All the tests have been carried out with a propeller revolution speed equal to the model self-propulsion point at $\mathrm{Fn}=0.083$. This value was determined in preliminary tests to be $57 \mathrm{rpm}$ at full scale. For the rpm corresponding to $\mathrm{Fn}=0.083$ in calm water, the rudder angle was varied from $-35^{\circ}$ to $35^{\circ}$.

The longitudinal and lateral rudder forces as well as the rudder moment have been measured by a rudder dynamometer and the results are referring to the rudder stock.

\subsection{Selected results DTC}

The first step of testing was the establishment of the propeller open water characteristics. The model scale results (scale 1:63.65) obtained in MARINTEK's towing tank for $13.78-\mathrm{Hz}$ propeller revolution are shown in Fig. 20 as a diagram. The open water 


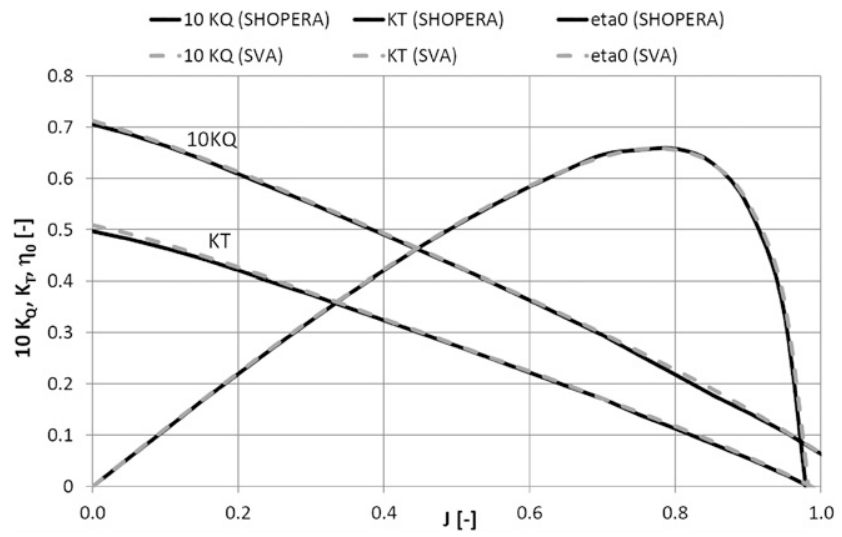

Fig. 20 Model scale open water diagram for the DTC propeller comparing data measured at MARINTEK (scale 1:63.65) and SVA Potsdam (scale 1:59.406, see El Moctar et al. 2012)

characteristics of the DTC propeller were earlier established at another facility, namely SVA Potsdam at a different scale (1:59.406, see Fig. 21). Both measurements agree quite well. The results from the tests at MARINTEK can be read from Table 4.

For the propulsion tests in waves, the DTC model was tested at design draft and parameters of variation were the propeller rpm and the wave period. One calm water reference run, 10 runs in regular waves, and 3 runs in irregular waves have been conducted. However, the iterative approach to find the correct setting to obtain a mean speed corresponding to Fn 0.052 and 0.087 , respectively, in each wave condition led to a higher number of runs. For each wave period, two wave heights have been tested.

Table 4 Results of open water model tests with the DTC propeller at MARINTEK (scale 1:63.65, $n=13.78 \mathrm{~Hz}$ )

\begin{tabular}{lrcr}
\hline $\mathrm{J}[-]$ & $\mathrm{K}_{\mathrm{T}}[-]$ & $10 \mathrm{~K}_{\mathrm{Q}}[-]$ & $\eta_{\mathrm{o}}[-]$ \\
\hline 0.00 & 0.497 & 0.706 & 0.000 \\
0.05 & 0.482 & 0.687 & 0.056 \\
0.10 & 0.464 & 0.664 & 0.111 \\
0.15 & 0.444 & 0.638 & 0.167 \\
0.20 & 0.421 & 0.609 & 0.220 \\
0.25 & 0.397 & 0.58 & 0.273 \\
0.30 & 0.374 & 0.551 & 0.325 \\
0.35 & 0.349 & 0.52 & 0.375 \\
0.40 & 0.324 & 0.49 & 0.422 \\
0.45 & 0.299 & 0.459 & 0.468 \\
0.50 & 0.274 & 0.428 & 0.510 \\
0.55 & 0.248 & 0.396 & 0.549 \\
0.60 & 0.222 & 0.363 & 0.585 \\
0.65 & 0.196 & 0.329 & 0.617 \\
0.70 & 0.171 & 0.295 & 0.647 \\
0.75 & 0.140 & 0.256 & 0.656 \\
0.80 & 0.112 & 0.217 & 0.658 \\
0.85 & 0.083 & 0.178 & 0.629 \\
0.90 & 0.054 & 0.143 & 0.540 \\
0.95 & 0.023 & 0.106 & 0.329 \\
1.00 & -0.012 & 0.062 & -0.310 \\
\hline
\end{tabular}

$[-]$ indicate dimensionless values
Despite the well-tuned and operated online autopilot, severe course-keeping problems were encountered for all regular waves $\lambda / L_{p p}>0.2$ after a certain number of encountered waves. During the tests, it became clear that the free-running model is not controllable in regular waves with an encounter period close to the vessel's natural periods in heave and pitch. The motions become very high and the vessel was trapped in a "locked" situation, where an increase of propeller revolutions does not led to an increase of forward speed until a certain threshold was passed and the vessel speed suddenly "jumped" up and the motions decreased again. The overall behavior in regular waves with an encounter period close to the vessel's natural period in pitch can be characterized as unstable. Therefore, the tests in longer waves were run with a slightly increased mean forward speed, namely $\mathrm{Fn}=0.087$, against the waves, instead of $\mathrm{Fn}=0.052$ (blue colored triangles in Fig. 21 refer to $\mathrm{Fn}=0.087$, red colored triangles to $\mathrm{Fn}=0.052$ ). A maximum rudder angle of $2^{\circ}-4^{\circ}$ was required to keep course.

From Fig. 21 it becomes also clear that the propulsion characteristics such as propeller thrust, torque, and revolutions are influenced by the presence of waves. Although the measured values for the mean speed corresponding to $\mathrm{Fn}=0.052$ in the shortest wave $\left(\lambda / L_{p p}=0.11\right)$ are very close to the calm water values for the same speed (red squares), the measured values for $\mathrm{Fn}=0.087$ and longer regular waves $\left(0.44<\lambda / L_{p p}<1.0\right)$ are clearly higher than for the associated calm water case (blue squares). It can be further observed that thrust, torque, and rpm reach a maximum for $\lambda / L_{p p}=0.85$, which is close to the vessel's natural period in pitch, where added resistance is very high. Another observation is that also an increase in wave height for the same period leads to a clear increase in thrust, torque, and revolutions to maintain the same mean forward speed.

Figure 22 shows the results of the bollard pull tests with the DTC at model scale: the graphs show the longitudinal rudder force, the lateral rudder force, the rudder moment, and the pull force for three different propeller revolution settings, corresponding to $30 \%, 75 \%$, and 100\% Maximum Continuous Rating (MCR). These model tests have been performed at Froude Law identity and at a rather small scale (propeller diameter $d=140 \mathrm{~mm}$ ), where viscous effects are

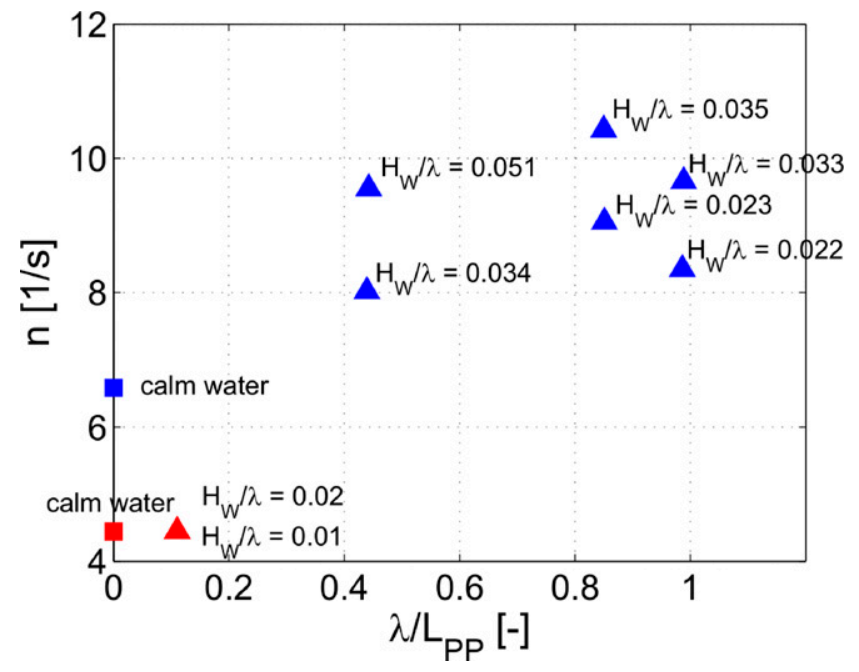

Fig. 21 Mean thrust (top) and torque (center) and revolution measurements in calm water (squares) and regular head waves (circles) for $\mathrm{Fn}=0.052$ (red) and $\mathrm{Fn}=0.087$ (blue) mean vessel speed, showing the influence of wave parameters (all values model scale) 


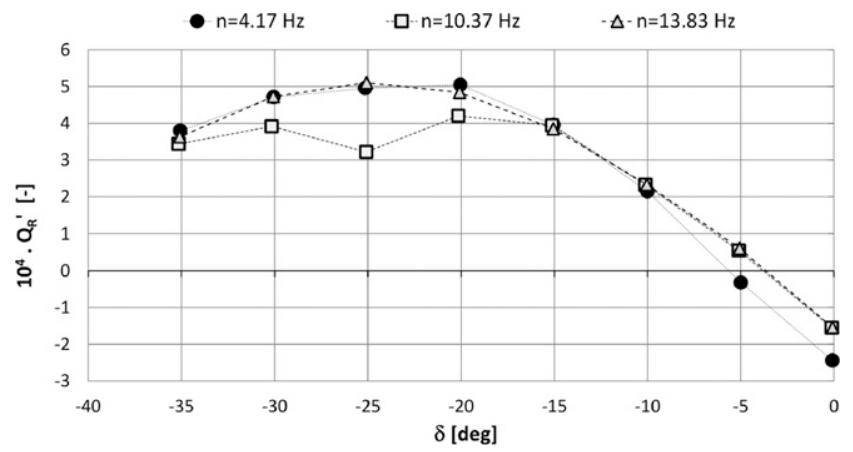

Fig. 22 Selected results of bollard pull tests with the DTC model in calm water from top to bottom: longitudinal rudder force, lateral rudder force, rudder moment and pull force for three different propeller revolution settings (corresponding to $30 \%, 75 \%$, and $100 \% \mathrm{MCR}$ )

expected not to be scaled correctly; especially for the lowest two RPM settings, the propeller is operating below $\mathrm{Re}=2.0 \times 10^{5}$. This together with the fact that rudder stall occurs already for the smaller rudder angles at model scale, than at full scale, explains the fluctuations that are observable in the longitudinal rudder forces.

\subsection{Selected results KVLCC2}

Rudder forces were also measured during tests in calm water and in waves at CEHIPAR. In Fig. 23, a comparison between the rudder lift forces for a test in calm water and in waves is shown. The vessel speed is $\mathrm{Fn}=0.082$ and the wave is $\lambda / L_{p p}=0.5$ and $\mathrm{H} / \lambda=0.025$. The forces for the case of $60^{\circ}$ heading is the closest one to the calm water case, whereas the case for $120^{\circ}$ of heading presents higher values.

There is a slight asymmetry between both sides of the curve caused by the asymmetry of the propeller flow and the wave velocity field.

\section{Maneuvering in waves}

The maneuverability of ships is addressed by IMO Standards for Ship Maneuverability, adopted in 2002 (see IMO 2002), which

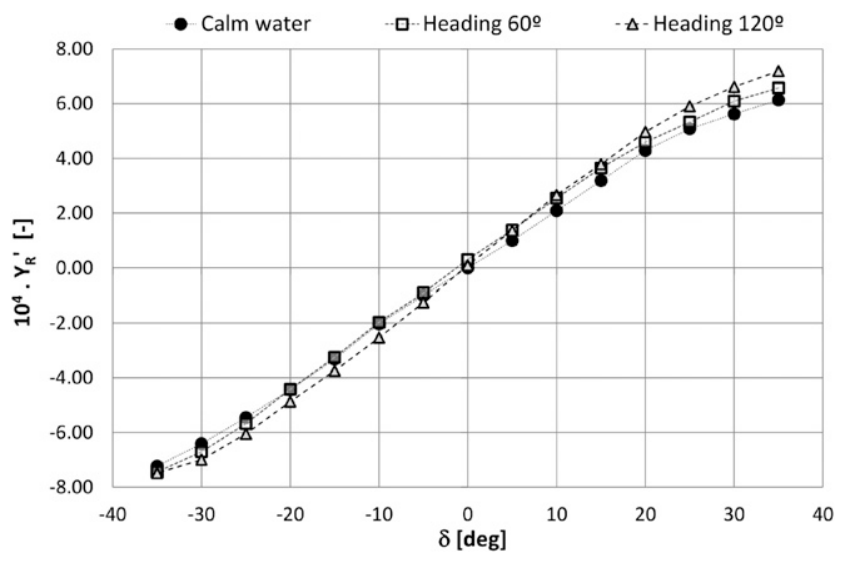

Fig. 23 Comparison of rudder forces for the KVLCC2 in calm water and regular waves from different headings

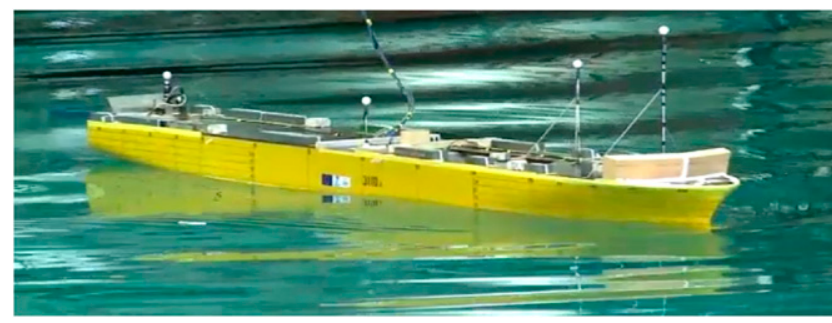

Fig. 24 Impression of the free-running DTC model performing maneuvering tests in waves in MARINTEK's Ocean Basin

assess turning ability (the ability of ship to turn using hard-over rudder), initial turning ability (i.e., the course-changing ability), yawchecking ability, course-keeping ability, and emergence-stopping ability, which are evaluated in simple maneuvers in calm water. These standards have been often criticized for not addressing ship maneuvering characteristics at low speed, in restricted areas, and in adverse weather conditions.

Experimental benchmark data for calm water maneuvers as well as an overview on the capabilities of state-of-the-art numerical methods are available from, e.g., the SIMMAN workshops (Stern et al. 2011).

However, the availability of both experimental benchmark data and validated numerical methods to assess maneuverability in waves is limited. Therefore, special attention has been paid to this test type in the compilation of the model test matrix for the research project SHOPERA.

Maneuvers such as turning circles and zig-zags were performed in calm water and in regular waves of different periods and height with different initial headings. It should be noted that the latter tests are not defined IMO conform maneuvers and the results are not comparable to calm water results in classic quantities such as the tactical diameter or the overshoot angle. The purpose of these tests is to gain insight into the maneuverability of vessels in the presence of waves in a broader and more general sense. First validation results for the numerical methods developed within SHOPERA to predict maneuverability in waves are presented in El Moctar et al. (2016) Cura-Hochbaum and Uharek (2016), and Papanikolaou et al. (2016).

\subsection{Experimental setup DTC}

Turning circle $\left(35^{\circ}\right.$ rudder angle) and $20^{\circ} / 20^{\circ}$ zig-zag maneuvers in calm water and regular waves were performed with the free-running DTC model (connected by an umbilical to a manually controlled gondola following the model, Fig. 24) at MARINTEK's ocean basin. Heading and propulsion settings were controlled by MARINTEK's online autopilot software NEMO, with an applied

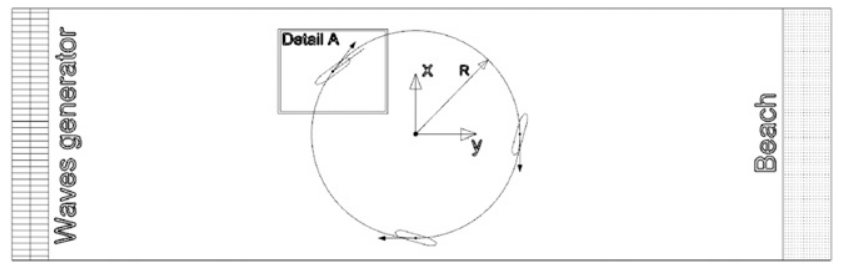

Fig. 25 Sketch of trajectory for captive circles in waves 
rudder rate of $3.0 \% \mathrm{sec}$ model scale (corresponding to $25 \% \mathrm{sec}$ full scale). The online PD regulator of the autopilot software was tuned by experienced MARINTEK staff to find the optimum settings (constant RPM approach) for the tests and to achieve the same initial vessel speed $(\mathrm{Fn}=0.052)$ prior to rudder execution. The instrumentation consists of a rudder servo for the autopilot, a dynamometer to measure thrust, and torque, the optoelectronic position measuring system OQUS for measurement of motions in 6DOF and four conductive wave tapes to measure the relative waves elevation at the port side fore shoulder of the hull.

The majority of tests were performed with the rudder set to starboard. Additional runs have been conducted to investigate the differences in maneuvering behavior when the rudder is set to portside, caused by the single screw propeller and twisted rudder setup of the DTC. The evaluation of the test data revealed that the rudder of the DTC model was mounted approximately $3^{\circ}$ off the true zero angle toward portside, leading to pronounced differences between maneuvers over portside and starboard side. Repetitions of the calm water turning circle maneuvers showed a deviation of less than $1 \%$ in tactical diameter and advance.

\subsection{Experimental setup KVLCC2}

The simulation of turning circles in waves by CEHIPAR was performed by attaching the model to a six-component dynamometer, which is fixed to the carriage, thus setting the model in a fully captive way (no sink, trim, or heel). The forces due to the turning and wave influence can be measured. Special care was taken to avoid the influence of wave reflection during these tests. In Fig. 25, a sketch of the arrangement is shown.

\subsection{Selected results DTC}

The test matrix comprises a total of 17 turning circle maneuvers, 2 calm water reference runs, 14 runs in regular waves (parameters of variation: initial heading, rudder direction, wave period, wave height), and 1 run in irregular seas.

In addition, five $20^{\circ} / 20^{\circ}$ zig-zag maneuvers have been performed, one calm water reference run and five runs in regular head waves (parameters of variation: wave period and timing of rudder execution relative to crest/trough). The comparison of the phasing of the rudder execution revealed a negligible influence on the characteristics of the maneuvers with differences of $2 \%-3 \%$ for overshoot angles and timing. These differences are in the range of accuracy of maneuvering tests in waves and it is difficult to draw conclusions with respect to the influence of phase shift on the maneuvering characteristics.

In Fig. 26, examples of the influence of the initial wave heading on the trajectory during the maneuver are shown. The vessel trajectories in the $\mathrm{x}-\mathrm{y}$ plane in waves are compared to a reference trajectory run in calm water (solid line). The approach speed for all cases is corresponding to $\mathrm{Fn}=0.052$ and the results are synchronized with respect to rudder execution $\left(35^{\circ}\right.$ to starboard). In head sea conditions (dashed line), the first circle requires less space

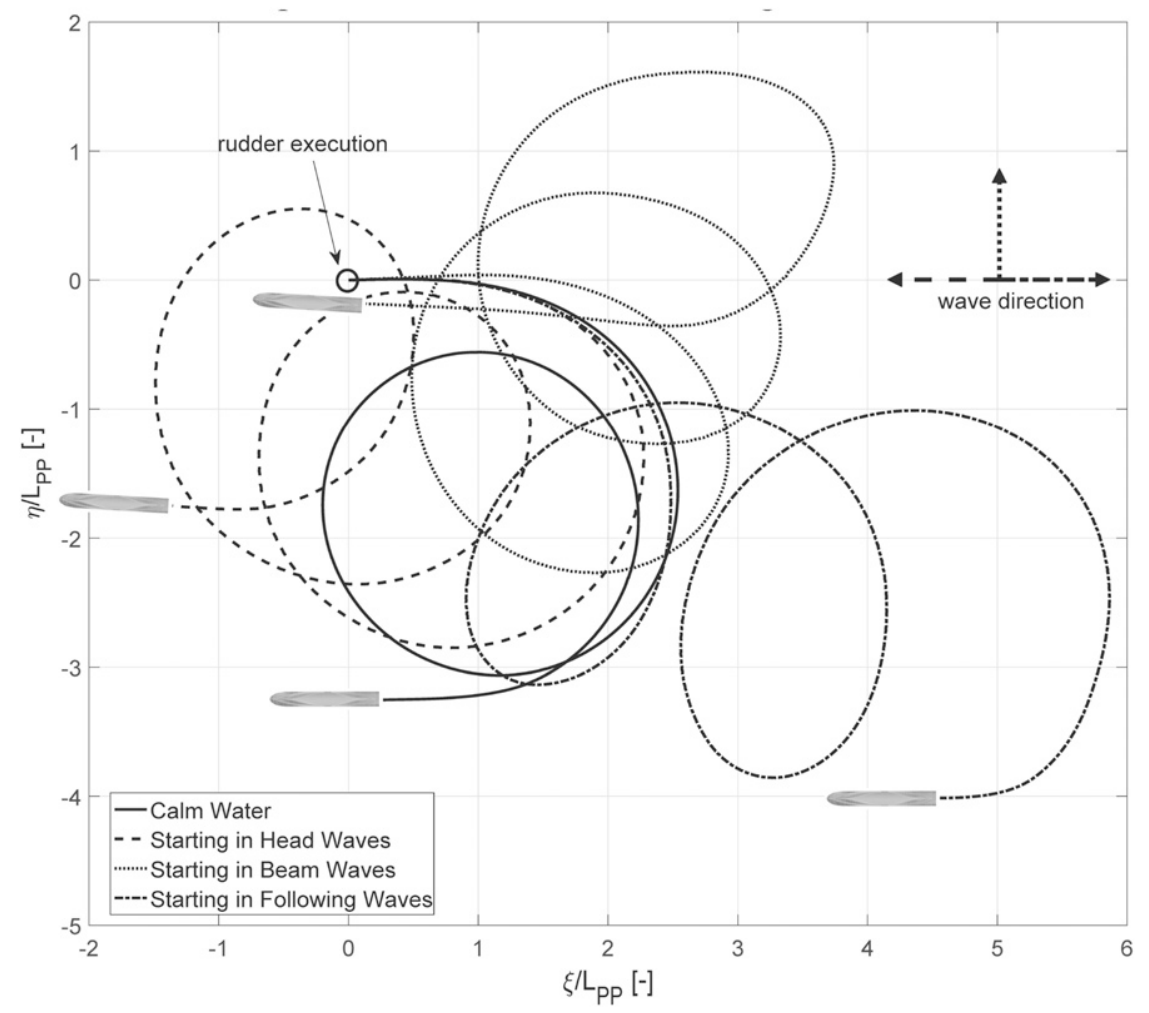

Fig. 26 Trajectories of the DTC performing turning circle maneuvers (rudder $35^{\circ}$ to starboard) in MARINTEK's Ocean Basin in calm water (solid), head waves (dashed), beam waves (dotted) and following waves (dash-dotted); tests have been conducted in regular waves with $\mathrm{H} / \lambda=0.011$ and $\lambda / L p p=0.494$ 


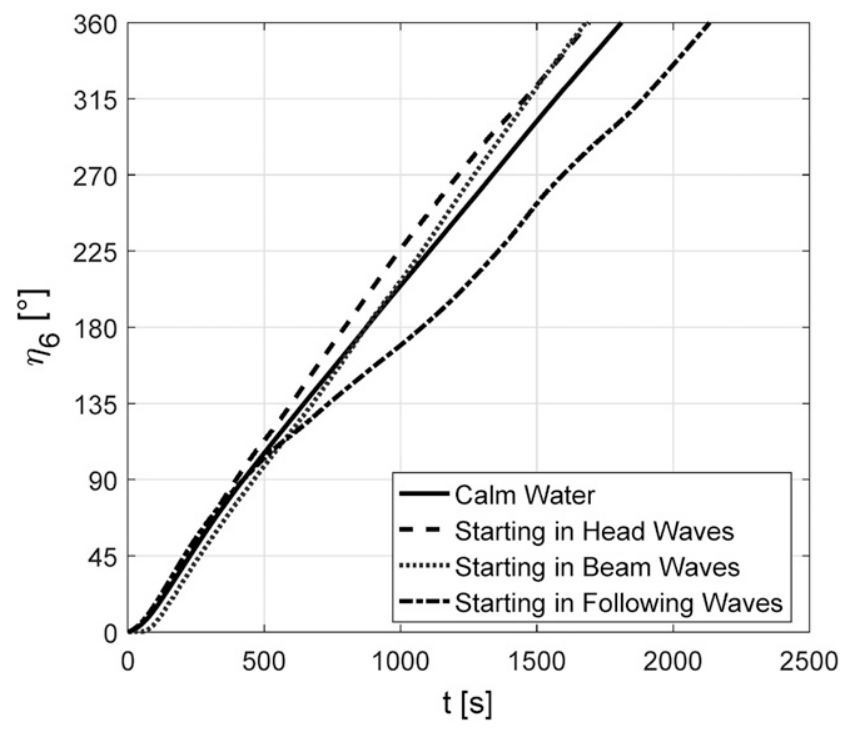

Fig. 27 Time series of the vessel heading during the turning circle maneuvers in calm water (black dashed), head waves (light gray solid), beam waves (black solid) and following waves (light gray dashed)

compared to the calm water reference run, and as apparent from Fig. 26, it takes the vessel approximately the same time to change heading by $90^{\circ}$ as in calm water, while a turn over $180^{\circ}$ takes less time than for the calm water case. The head waves push against the bow and thus amplify the effect of the moment produced by the rudder. The vessel is drifting oblique with the direction of wave propagation. This is caused by the wave moment acting against the rudder moment when the ship is turning from $180^{\circ}$ to $270^{\circ}$. In following sea conditions, the (dash-dotted) trajectory of the vessel is strongly distorted by the pronounced drift motion between consecutive turns; here, the wave moment amplifies the effect of the rudder moment when the ship is turning from $180^{\circ}$ to $270^{\circ}$. In this condition, it takes approximately the same time to turn $90^{\circ}$ as in calm water, whereas it takes significantly longer to turn by $180^{\circ}$ (see Fig. 27). When the vessel approaches the maneuver in beam seas and initially turns the bow into the waves (dotted line), it takes slightly longer to turn $90^{\circ}$, while the time required to turn by $180^{\circ}$ is approximately the same as in calm water (see Fig. 27).

An example of the influence of regular head waves on the course changing ability of the DTC vessel is presented in Fig. 28, where three $20^{\circ} / 20^{\circ}$ zig-zag maneuvers with $\mathrm{Fn}=0.052$ approach speed are compared. The black lines show the yaw angle (solid) and rudder angle (dashed) as a function of time in calm water (full

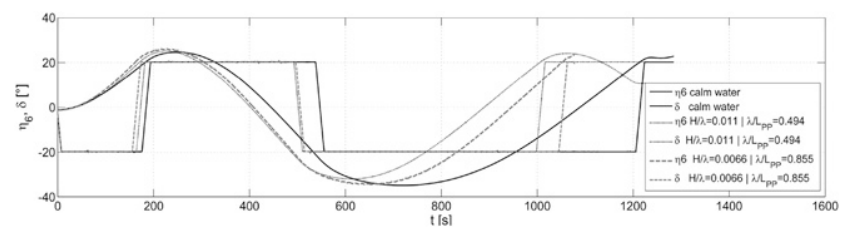

Fig. 28 Yaw and rudder angle of the DTC performing $20^{\circ} / 20^{\circ}$ zig-zag maneuvers in MARINTEK's Ocean Basin in calm water (black) and regular head waves with $\mathrm{H} / \lambda=0.011, \lambda / p p=0.494$ (dotted), and $\mathrm{H} / \lambda=0.0066$, $\lambda / L p p=0.855$ (dashed)

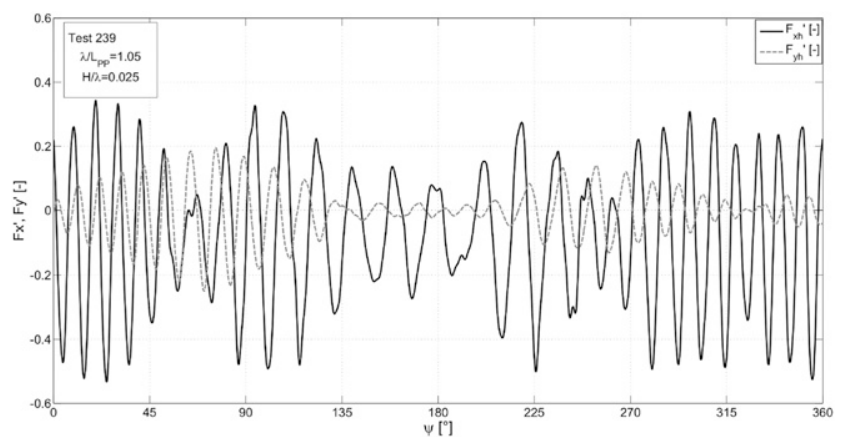

Fig. 29 Example of longitudinal and lateral forces during a captive circular turns in waves

scale), the dotted and dashed lines represent the regular head wave cases (dotted: $\mathrm{H} / \lambda=0.011, \lambda / L_{p p}=0.494$; dashed: $\mathrm{H} /$ $\lambda=0.0066, \lambda / L_{p p}=0.855$ ). All three cases are synchronized with respect to first rudder execution, which has been performed with wave crest at $L_{p p} / 2$ (FP) for the cases with waves. Although the first (and second) overshoot angle and initial turning time are similar for all three cases, the differences become more pronounced for reach and time for the complete cycle. In head waves, the vessel requires less time to reach zero heading after the first and third rudder execute. The shortest duration for the completion of the maneuver is observed for the longer wave period $\left(\lambda / L_{p p}=\right.$ $0.855)$.

\subsection{Selected results KVLCC2}

Systematic captive circular motion tests in waves were performed at CEHIPAR for different combination of wave frequency, circle radius, drifting angle, and velocities. Figure 29 shows an example of the measured Fx' and Fy' forces on the model during a test with a drift angle of $20^{\circ}$ and circle radius of $R / L_{p p}=1.5$.

\section{Discussion on experimental error range}

Since the presented test campaign encompasses a very large number of individual test conditions, it was not feasible to perform in depth uncertainty analysis studies for every test and thus to assign an error bar to each result that is herein presented. However, all tests were conducted following professional standards of the participating experimental facilities and relevant ITTC recommendations (ITTC 2008a, 2008b); the following examples were selected to exemplarily discuss the expected error ranges.

In order to illustrate the uncertainty in force measurements, it is assumed that the measured signals have a mean value $\mu_{x}$ and an estimated standard deviation $\sigma_{x}$ given as follows:

$$
\mu_{x}=\sum_{i}^{N} x_{i} \text { and } \sigma_{x}=\sqrt{\sum_{i=1}^{N} \frac{\left(x_{i}-\mu_{x}\right)^{2}}{N-1}}
$$

If a variable is a function of multiple signals, all with their own uncertainties, then the term propagation uncertainty is used to calculate the mean and the standard deviation of the variable $(y)$. The standard deviation is calculated based on the Fourier expansion, assuming that no correlation between the variables exists (all variables are assumed independent and random). 


$$
\begin{aligned}
y & =f\left(x_{1}, x_{2}, \ldots, x_{i}, \ldots, x_{n}\right) \\
\mu_{y} & =f\left(\mu_{1}, \mu_{2}, \ldots, \mu_{i}, \ldots, \mu_{n}\right) \\
\sigma_{y}^{2} & =\sqrt{\sum_{i=1}^{n}\left(\frac{\partial f}{\partial x_{i}}\right)^{2} \cdot \sigma_{x, i}{ }^{2}}
\end{aligned}
$$

The described methodology is herein applied to estimate the uncertainty of longitudinal force measurements in captive towing tests at FHR. In the initial phase of each added resistance test, the model is accelerated in calm water to the desired speed and is being towed at the target speed for a certain time window before encountering the first waves. For the Fn $=0.052$ target speed tests with the DTC $(100 \%$ and $20 \%$ UKC) and the Fn $=0.055$ tests with the KVLCC2 ( $30 \%$ and $20 \%$ UKC), these time windows are of sufficient length to determine the longitudinal forces for each run in calm water. On this basis, mean values and standard deviations for the measured forces have been calculated.

As illustrated in Table 5, the deviation on the longitudinal force in calm water for DTC at $100 \%$ UKC and Fn $=0.052$ is $0.02 \mathrm{~N}$. Assuming that the deviation for force measurements in waves is of the same magnitude and using uncertainty propagation, the combined uncertainty would be $0.028 \mathrm{~N}$. For the presented cases, the magnitude of added resistance is significantly larger than the estimated deviation. Similar deviation magnitudes have been estimated for longitudinal force measurements in towing tests at MARINTEK: for the DTC tests at Fn $=0.052$, the mean longitudinal forces in calm water are $1.85 \mathrm{~N}$ with a standard deviation of $0.05 \mathrm{~N}$.

Another example is the estimated error range for the free-running maneuvering test. Selected maneuvers in calm water and waves have been repeated at MARINTEK. Calm water turning circles with $\mathrm{Fn}=0.052$ initial speed and $35^{\circ}$ starboard rudder show a deviation in tactical diameter of $1 \%$, whereas turning circles with the same speed and rudder setting in regular waves $\left(\lambda / L_{p p}=0.49\right.$, $\mathrm{H} / \lambda=0.0114)$ reveal a deviation of $2 \%$ in tactical diameter. It has to be noted that the timing of rudder execution was random with respect to the local wave elevation along the hull.

\section{Review of results and conclusions}

This article presented typical results of the unique, broad experimental campaign of the EU-funded project SHOPERA, which was run with two public domain hull models of different hydrodynamic characteristics-namely the DTC containership and the KVLCC2 tanker-by four of the leading European maritime experimental facilities, namely MARINTEK, CEHIPAR, FHR, and

Table 5 Mean values and standard deviations for longitudinal force measurements with the DTC and KVLCC2 in different testing conditions

\begin{tabular}{lrrrcc}
\hline Ship & UKC & Fn $[-]$ & $\mu_{\mathrm{X}}(\mathrm{N})$ & $\sigma_{\mathrm{X}}(\mathrm{N})$ & No. of tests \\
\hline DTC & 100 & 0.052 & -0.86 & 0.02 & 26 \\
DTC & 20 & 0.052 & -1.06 & 0.05 & 26 \\
KVLCC2 & 30 & 0.055 & -2.02 & 0.03 & 15 \\
KVLCC2 & 20 & 0.055 & -2.23 & 0.04 & 23 \\
\hline
\end{tabular}

[-] indicate dimensionless values
TUB. The purpose of the performed model tests was to contribute to the establishment of a benchmark and validation database that addresses seakeeping and maneuvering in waves in different environmental conditions and water depths. The database is of paramount importance for the validation of numerical prediction methods and software tools (see, Liu et al. 2016 for conducted International Benchmark) and the development of procedures to assess ship's performance in waves and to formulate minimum powering requirements to ensure safe ship operation in adverse weather conditions, while keeping the right balance between ship economy, efficiency, and safety (see, IMO 2016a-2016c).

The presented data samples were selected to highlight the influence of wave climate, vessel heading, and water depth on added resistance and drift forces for different vessel types. The key findings from the comparison and assessment of selected results are as follows:

- An overall fair agreement of results obtained by different experimental facilities can be observed, with no significant deviations caused by the different test setups of the involved facilities.

- Added resistance coefficients in most cases increase with decreasing water depth; however, this trend may reverse in the short length and lower amplitude waves region (see Fig. 12), while vessel's speed (Froude number) may have also a significant effect on the observed trends. The fundamental squared-amplitude relation for the added resistance was confirmed for longer waves in deep water, where the coefficients obtained for different wave amplitudes are only marginally different. However, for short waves in deep water and for very small wave amplitudes, this relationship appears to be questionable. Here, the added resistance coefficients clearly decrease with increasing regular wave amplitude, indicating that the squared wave amplitude dependence of the added resistance does not apply anymore. This observation was also confirmed by others, namely the added resistance measurements performed for the KVLCC2 hull at Fn $=0.142$ and two different regular wave amplitudes (Yasukawa et al. 2016).

- For large vessels especially the short relative waves range is of paramount importance, because of the higher probability to meet these waves in practice. This leads to challenges for the testing facilities, when it comes to scales and accuracies for both the generation of the incident waves and the measurement of the associated forces on ship's hull.

- For the DTC, the added resistance becomes negative at $\mathrm{Fn}=0.052$ for certain period/wave length regions in stern quartering and following seas. This means that the vessel actually experiences a pushing effect ("added thrust") from the waves.

- The influence of the boundary layer of the bottom flow of the shallow water towing tank on added resistance for very small UKC was not known/explored yet.

- The propulsion tests in waves revealed that the necessary adjustment to achieve a mean forward speed against regular waves is dependent on the wave length and height. While the difference to the calm water case is negligible for the short relative wave lengths, propeller thrust, torque, and revolutions have to increase for longer waves in order to maintain the desired speed. Maximum values are reached around the maximum for the added resistance.

- TUB developed a new platform and measuring technique for the forces and motions in waves and employed it to obtain a 
comprehensive data set for the DTC model. The technique has shown to be accurate and offers great possibilities for further research. In order to determine the pure hydrodynamic forces and moments acting on the model, inertial effects were subtracted from the measured time traces. Inertial force contributions were found to be of significant importance for the ship sailing at moderate speed.

- Further model test data show the open water characteristics of the propeller and the rudder forces in calm water and in waves for different propeller revolutions and rudder angles.

Experimental investigations of maneuvers performed in regular waves with different initial heading illustrate the importance of considering the presence of waves, when assessing the maneuverability of a vessel. The comparison of results from selected turning circle and zig-zag tests with the DTC model in waves and calm water in MARINTEK's Ocean Basin reveals

- Turning circles performed with initial head or beam sea conditions require the least space and time, while turning circles performed in initial following seas require the most space and time.

- Turning $90^{\circ}$ in beam seas takes longer than for all other investigated cases, whereas a $180^{\circ}$ turn takes about the same time as in calm water conditions.

- Turning $180^{\circ}$ in head seas requires less time than in calm water.

- Turning $90^{\circ}$ in following seas takes less time than for all other investigated cases, whereas a $180^{\circ}$ turn takes the more time than in all other investigated cases.

The conducted experimental work of more than 1300 different tests for the maneuvering and hydrodynamic performance of ships in waves is an unprecedented research effort and invaluable source of information, the detailed analysis of which will take some years to be completed. On the basis of parts of this experimental work, Project SHOPERA organized an international benchmark study, in which close to 20 numerical codes of varying complexity did comparative calculations for a variety of measured hydrodynamic quantities. Preliminary results of the outcome of this benchmark were presented in a public workshop in April 2016 (Potthoff et al. 2016; Liu et al. 2016). In short, the outcome of this benchmark, which concentrated on tests cases in the short waves regime, was rather disappointing, indicating that the international state of the art has not much progressed in recent years and it will take some more years to come to satisfactory levels.

\section{Acknowledgments}

The authors acknowledge the contributions of all SHOPERA partners. The work presented in this paper is supported by the Collaborative Project SHOPERA (Energy Efficient Safe SHip OPERAtion), Grant Agreement number 605221, http://www. shopera.org, co-funded by the Research DG of the European Commission within the RTD activities of the FP7 Thematic Priority Transport, FP7-SST-2013-RTD-1, Activity 7.2.4 Improving Safety and Security, SST.2013.4-1: Ships in Operation. The European Community and the authors shall not in any way be liable or responsible for the use of any knowledge, information or data of the present paper, or of the consequences thereof. The views expressed in this paper are those of the authors and do not necessarily reflect the views and policies of the European Community.

\section{References}

Boom, H. V. D., Huisman, H., and Mennen, F. 2013 New guidelines for speed/ power trials: Level playing field established for IMO EEDI, SWZ Maritime, Schip en Werf de Zee Foundation, Rotterdam.

Cura Hochbaum, A. And UhareK, S. 2016 Prediction of ship manoeuvrability in waves based on RANS simulations, Proceedings, The $31^{\text {st }}$ ONR Symposium on Naval Hydrodynamics, September 11-16, Monterey, CA.

Clauss, G., Lehmann, E., And ÖstergaArd, C. 1992 Offshore Structures Volume I: Conceptual Design and Hydromechanics, London, UK: SpringerVerlag.

Delefortrie, G., Geerts, S., And Vantorre, M. 2016 The towing tank for manoeuvres in shallow water, Proceedings, The $4^{\text {th }}$ International Conference on Ship Manoeuvring in Shallow and Confined Water, May 23-25, Hamburg, Germany.

El Moctar, O., Shigunov, V., and Zorn, T. 2012 Duisburg test case: PostPanamax container ship for benchmarking, Journal of Ship Technology Research, 59, 3, 50-64.

El Moctar, O., Sprenger, F., Schellin, T., and Papanikolaou, A. 2016 Numerical and experimental investigations of ship maneuvers in waves, proceedings, The $35^{\text {th }}$ International Conference on Ocean, Offshore and Arctic Engineering, June 19-24, Busan, South Korea.

Faltinsen, O. M., Minsaas, K. J., Liapis, N., and SkJørdal, S. O. 1980 Prediction of resistance and propulsion of a ship in a seaway, Proceedings, $13^{\text {th }}$ Symposium on Naval Hydrodynamics, October 6-10, Tokyo, Japan.

FuJII, H. AND TAKAHASHI, T. 1975 Experimental study on the resistance increase of a ship in regular oblique waves, Proceeding, $14^{\text {th }}$ ITTC, Vol. 4, September 1975, Ottawa, Canada, pp. 351-360.

Guo, B. And SteEn, S. 2010 Added resistance of a VLCC in short waves, Proceedings, The $29^{\text {th }}$ International Conference on Ocean, Offshore and Arctic Engineering, June 6-11, Shanghai, China.

Hirano, M., Takashina, J., Takeshi, K., and Saruta, T. 1980 Ship turning trajectory in regular waves, Transactions of West-Japan Society of Naval Architects, 60, 17-31.

Huissmans, R. 1996 Mathematical modelling of the mean wave drift force in current, PhD thesis, Technische Universiteit Delft, Delft, the Netherlands.

JourNÉE, J. M. J. 1992 Experiments and calculations on 4 Wigley hull forms in head waves, Ship Hydrodynamics Laboratory Report 0909, Delft University of technology, Delft, the Netherlands.

International Towing Tank Conference (ITTC). 2008a Guide to the expression of uncertainty in experimental hydrodynamics (7.5-02-01-01). ITTC-Recommended Procedures and Guidelines.

InTERNATIONAL TOWING TANK CONFERENCE (ITTC). 2008b Uncertainty analysis instrument calibration (7.5-01-03-01). ITTC-Recommended Procedures and Guidelines.

InTERnAtional Towing TANK Conference (ITTC). 2011 Seakeeping tests (7.502-05-04). ITTC—Recommended Procedures and Guidelines.

International Towing Tank Conference (ITTC). 2014 Final report and recommendations of the Specialist Committee on Performance of Ships in Service to the $27^{\text {th }}$ ITTC, Proceedings, The $27^{\text {th }}$ International Towing Tank Conference, August 31-September 5, Copenhagen, Denmark.

KashiwaGi, M. 2013 Hydrodynamic study on added resistance using unsteady wave analysis, Journal of Ship Research, 57, 4, 220-240.

Lee, S., Hwang, S., Yun, S., Rhee, K., and Seong, W. 2009 An experimental study of a ship manoeuvrability in regular waves, Proceedings, The International Conference on Marine Simulation and Ship Manoeuvrability, August 17-20, Panama City, Panama.

Liu, S. and Papanikolaou, A. 2016 Fast approach to the estimation of the added resistance of ships in head waves, Ocean Engineering, 112, 211-225.

Liu, S., Papanikolaou, A., Potthoff, R., El Moctar, O., and Shigunov, V. 2016 International Benchmark Study on Numerical Simulation Methods for the Prediction of Added Resistance and Manoeuvrability of Ships in Waves. Project SHOPERA. Available at http://www.shopera.org.

MARUO, H. 1963 Resistance in waves. $60^{\text {th }}$ anniversary series, The Society of Naval Architects of Japan, 8, 67-102.

Papanikolaou, A., Zaraphonitis, G., Bitner-Gregersen, E., Shigunov, V., El Moctar, O., Guedes Soares, C., Devalapalli, R., and Sprenger, F. 2014 Energy efficient safe ship operation (SHOPERA), Proceedings, The 
RINA Conference on the Influence of the EEDI on Ship Design, September 24-25, London, UK.

Papanikolaou, A., Zaraphonitis, G., Bitner-Gregersen, E., Shigunov, V., El Moctar, O., Guedes Soares, C., Devalapalli, R., and Sprenger, F. 2015a Energy efficient safe ship operation, Proceedings, The SNAME World Maritime Conference, November 3-7, Providence, RI.

Papanikolaou, A., Zaraphonitis, G., Bitner-Gregersen, E., Shigunov, V., El Moctar, O., Guedes Soares, C., Devalapalli, R., and Sprenger, F. 2015b Energy efficient safe ship operation (SHOPERA), Proceedings, The $12^{\text {th }}$ International Marine Design Conference, May 11-14, Tokyo, Japan.

Papanikolaou, A., Zaraphonitis, G., Bitner-Gregersen, E., Shigunov, V., El Moctar, O., Guedes Soares, C., Devalapalli, R., and Sprenger, F. 2015c Minimum propulsion and steering requirements for efficient and safe operation (SHOPERA), Proceedings, The $37^{\text {th }}$ Motorship Propulsion and Emissions Conference, March 4-5, Hamburg, Germany.

Papanikolaou, A., Fournarakis, N., Chroni, D., Liu, S., Plesssas, T., and SpRENGer, F. 2016 Simulation of the maneuvering behavior of ships in adverse weather conditions, Proceedings, The $31^{\text {st }}$ Symposium on Naval Hydrodynamics, September 11-16, Monterey, CA.

PARK, D.-M., LeE, J., AND KIM, Y. 2015 Uncertainty analysis for added resistance experiment of KVLCC2 ship, Ocean Engineering, 95, 143-156.

PINKSTER, J. A. 1980 Low frequency second order wave exciting force on floating structures, $\mathrm{PhD}$ thesis, Technische Hogeschool TU Delft.

Potthoff, R., El Moctar, O., and Papanikolaou, A. 2016 Presentation of Benchmark Results-SHOPERA Benchmark Workshop, London, April 15. Available at http://www.shopera.org/benchmark-study/.

SHOPERA. 2013-2016 Energy Efficient Safe SHip OPERAtion, FP7-SST2013-RTD-1, 2013-2016. Available at http://www.shopera.org (Accessed July 11, 2017).

SIMMAN. 2008 Workshop on Verification and Validation of Ship Manoeuvring Simulation Methods (SIMMAN 2008). Available at http:// www.simman2008.dk/KVLCC/KVLCC2/tanker2.html, status: 17.12.2015.

Sprenger, F., Hassani, V., Maron, A., Delefortrie, G., van Zwijnsvoorde, T., Cura-Hochbaum, A., and Lengwinat, A. 2016 Establishment of a validation and benchmark database for the assessment of ship operation in adverse conditions, Proceedings, The $35^{\text {th }}$ International Conference on Ocean, Offshore and Arctic Engineering, June 19-24, Busan, South Korea.

Stern, F., Agdrup, K., Kim, S. Y., Cura-Hochbaum, A., Rhee, K. P., Quadvlieg, F., Perdon, P., Hino, T., Broglia, R., And Gorski, J. 2011 Experience from SIMMAN2008-The First Workshop on Verification and Validation of Ship Maneuvering Simulation Methods, Journal of Ship Research, 55, 2, $135-147$.

Strom-Tejsen, J., Yeh Hugh, Y. H., and Moran, D. D. 1973 Added resistance in waves, Transactions of the Society of Naval Architects and Marine Engineers, 81, 109-143.

Tello Ruiz, M., De Caluwé, S., Van Zwijnsvoorde, T., Delefortrie, G., AND VANTORRe, M. 2015 Wave effects in 6 DOF on a ship in shallow water, Proceedings, The International Marine Simulation Forum, September 8-11, Newcastle, UK.

Tello Ruiz, M., Vantorre, M., Van Zwijnsvoorde, T., and Delefortrie, G. 2016 Challenges with ship model tests in shallow water waves, Proceedings, The $12^{\text {th }}$ International Conference on Hydrodynamics, Delft, September 18-23, the Netherlands.

Ueno, M., Nimura, T., and Miyazaki, H. 2003 Experimental study on manoeuvring motion of a ship in waves, Proceedings, The International Conference on Marine Simulation and Ship Manoeuvrability (MARSIM), August 25-28, Tokyo, Japan.

The International Maritime Organisation (IMO). 2002 Standards for ship manoeuvrability. MSC.137(76)

The International Maritime Organisation (IMO). 2013a Amendments to MARPOL Annex VI on regulations for the prevention of air pollution from ships by inclusion of new regulations on energy efficiency for ships. MEPC.203.

The International Maritime Organisation (IMO). 2013b Interim guidelines for determining minimum propulsion power to maintain the manoeuvrability in adverse conditions. MEPC.232(65).

The International Maritime Organisation (IMO). 2016a Results of research project "Energy Efficient Safe Ship Operation (SHOPERA)," submitted by Denmark, Germany, Norway and Spain, MEPC70/INF.33.

The International Maritime Organisation (IMO). 2016b Progress report of SHOPERA and Japan's projects and outline of draft revised Guidelines for determining minimum propulsion power to maintain the manoeuvrability of ships in adverse conditions, submitted by Denmark, Germany and Japan, MEPC70/5/20.
The International Maritime Organisation (IMO). 2016c Supplementary information on the draft revised Guidelines for determining minimum propulsion power to maintain the manoeuvrability of ships in adverse conditions, submitted by Denmark, Germany and Japan, MEPC70/INF.30.

Valanto, P. AND Hong, Y. 2015 Experimental investigation on ship wave added resistance in regular head, oblique, beam, and following waves, Proceedings, The $25^{\text {th }}$ International Ocean and Polar Engineering Conference (ISOPE), June 21-26, Kona, Hawaii, pp. 19-26, June 2015.

Xu, Y., Kinoshita, T., AND ITAKURA, H. 2007 A PMM experimental research on ship manoeuvrability in waves, Proceedings, The $26^{\text {th }}$ International Conference on Offshore Mechanics and Arctic Engineering, June 10-15, San Diego, CA.

YasuKawa, H. AND Adnan, F. A. 2006 Experimental study on wave-induced motions and steady drift forces of an obliquely moving ship, Journal of the Japan Society of Naval Architects and Ocean Engineers, 3, 133-138.

Yasukawa, H. and Nakayama, Y. 2009 6-DOF motion simulations of a turning ship in regular waves, Proceedings, The International Conference on Marine Simulation and Ship Manoeuvrability MARSIM'09, August 17-20, Panama City, Panama.

Yasukawa, H., Hirata, N., Yonemasu, I., Terada, D., And Matsuda, A. 2015 Maneuvering simulation of a KVLCC2 tanker in irregular waves, Proceedings, The International Conference on Marine Simulation and Ship Manoeuvrability MARSIM'15, September 8-11, Newcastle, UK.

Yasukawa, H., Matsumoto, A., And Ikezoe, S. 2016 Wave height effect on added resistance of full hull ships in waves, Journal of the Japan Society of Naval Architects and Ocean Engineers, 23, 45-54.

\section{Discussion}

\section{Hironori Yasukawa, Hiroshima University, Visitor}

1) This paper is really interesting, but I have a complaint. Review work is insufficient: there are no references about topics of wave-induced steady forces including added resistance and maneuverability in waves.

2) Added resistance tests in regular head waves have been carried out using a KVLCC 2 model with $2.90 \mathrm{~m}$ in ship length [1]. Main objective of the tests is to capture the wave height effect on the added resistance. Figure 30 shows the test result of added resistance coefficient in regular waves. The tests were carried out with changing the incident wave heights, 30 and $50 \mathrm{~mm}$. Load condition is scantling full. Ship speed is corresponding to $15.5 \mathrm{kN}$. The added resistance coefficients are normalized by square of the wave amplitude. The coefficients with wave height $50 \mathrm{~mm}$ are smaller than that with $30 \mathrm{~mm}$ as a whole. This means that added resistance in regular waves is strictly not proportional to square of incident wave amplitude, although the exponent should be two theoretically. This result is important for discussing the short-term prediction of added resistance in irregular waves based on the added resistance coefficients in regular waves. How was your test result of the added resistance with different wave heights?

\section{Armin Troesch, University of Michigan, Fellow}

The authors are to be congratulated on presenting a well-written and insightful paper on one of the possible consequences of Energy Efficiency Design Index (EEDI) implementation. As noted in the paper, reduced powering may be a reasonable way to limit undesirable emissions but may become counter-productive if the result is an inability to safely maneuver or maintain heading in severe seas.

The paper describes in detail the experimental program undertaken at four European test basins located in Belgium, Germany, Norway, and Spain. Dynamic testing, such as maneuvering in 


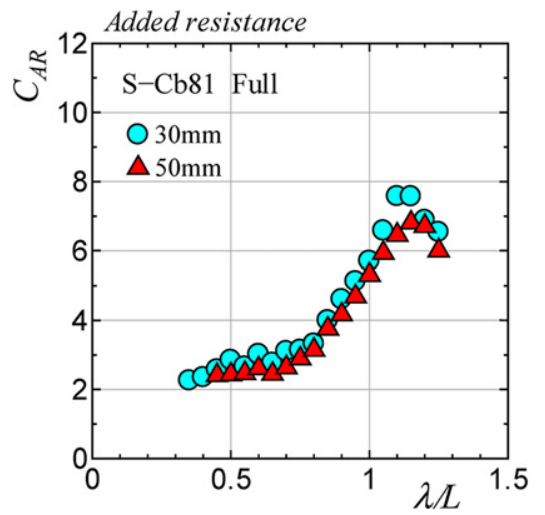

Fig. 30 Added resistance coefficients of KVLCC2 model with different wave heights, 30 and $50 \mathrm{~mm}$

waves and measuring added resistance and slow drift forces, is challenging due the inherent nonlinear behavior of the various processes. Since two different hull forms with varying scale ratios were used, these experiments provide an opportunity to quantify uncertainty in the measurements due to scale effects and variability in different experimental facilities. Do the authors plan on releasing detailed comparisons where the same hull forms (using possibly different scale ratios) are tested under identical test conditions in different basins? This information would go a long way toward establishing confidence intervals for these formidable, but important, experiments.

\section{Authors' Response}

First of all, the authors like to express their gratitude and appreciation to both discussers for their kind commendations and valuable questions, which we will be discussing in the following.

Professor Yasukawa's first comment referred to the limited review of past work in the subject area in the original paper, which we cured by adding a new section on the State of the Art of experimental methods and studies on the wave-induced steady forces, added resistance, and maneuverability of ships in waves.

We are in agreement with Professor Yasukawa's second comment on the degree of nonlinearity of the added resistance and the incident wave height, namely that the well-known quadratic dependence of the added resistance on the incident wave height does not hold for steeper waves. We had similar observations for steeper and shorter waves, whereas the quadratic law could only be confirmed for longer, less steep waves. This is in line with the underlying quasi second-order potential theory, which leads to the steady, second-order waveinduced forces (drift forces and added resistance), whereas the incident wave is assumed linear and with infinitesimally small wave height. Characteristically, increasing the incident wave steepness, as shown in KVLCC2 experiments by Yasukawa, the dimensionlessadded resistance coefficient decreases, which is a well-known observation regarding the effect of nonlinearities... in similar seakeeping/ship motion studies.

Professor Troesch discussed the uncertainty of experimental data, because of the complexity of the studied physical phenomena, the effect of a large number parameters and obvious limitations of the used hardware when measuring very small quantities and even if it is according to the current State of the Art and ITTC recommended procedures. This is in fact a wide field for discussion and further development is necessary ... until we come to acceptable confidence levels. We like to point out a few issues of distinct interest in relation to the studied subject, which we also addressed in the present paper:

1. Experiments in short waves: The shortness of waves, as related to the $\lambda / L$ ratio that may be less than about $0.5(0.7)$, puts a series of challenges to the experimental facilities and the testing hard-/software, both with respect to the generation of the exciting waves and the measured waveinduced responses in view of the small associated absolute values. This calls for larger ship models and higheraccuracy measuring systems. It is noted that this is the wave range of practical interest for large tankers, bulkcarriers, container and cruise ships (over about $200 \mathrm{~m}$ in length).

2. Wave steepness and breaking: This must be seen also in relation to the short waves range, both in view of wave statistics, especially in coastal waters, and in relation to the practice of testing facilities to increase the wave steepness in short wave conditions for better sensing the wave impact. Of course, increasing the wave steepness may cause wave breaking with all the associated consequences in terms of the processing of the measurements. In addition, an increased wave steepness resulting to a nonlinear (non Airy) wave challenges the well-established squared wave amplitude relationship to the drift forces and added resistance, which seems not anymore valid.

3. Experiments with irregular waves: Only very few (experimental and numerical) studies were performed until now for the added resistance and maneuvering in irregular seaways. The repeatability of results for given spectral density of the ensuing seaway is not ensured in view of the nonlinearities involved in several associated physical phenomena. For light seaways, one may expect that common spectral analysis techniques are still applicable, thus one may estimate ship's added resistance by use of RAO's from regular waves analysis.

4. Experiments in shallow water waves: Maneuvering experiments and studies in general in shallow water are limited, at least in public domain, even though of increased importance when discussing the safety of ships in view of grounding statistics. This type of studies is even more important when considering in parallel adverse weather conditions, which is the core research subject of project SHOPERA (Papanikolaou et al. 2014, 2015a). The effect of the shallowness of water on the added resistance and drift forces is not unique and dependent on incident wave's length, ship's speed, and UKC, as shown in the paper.

5. Testing by different facilities: In the present paper, we could in fact test two different, public domain hull forms (DTC and KVLCC2) by two pairs of different facilities (MARINTEK/ TUB and FHL/CEHIPAR) and to the extent the same tests were conducted we could conclude that the obtained results were comparable. 